Global COE Hi-Stat Discussion Paper Series 126

$$
\begin{aligned}
& \text { Research Unit for Statistical } \\
& \text { and Empirical Analysis in Social Sciences (Hi-Stat) }
\end{aligned}
$$

\title{
Small Business Set-asides in Procurement Auctions: An Empirical Analysis
}

Jun Nakabayashi

March 2010 
Small Business Set-asides in Procurement Auctions: An Empirical Analysis

by

Jun Nakabayashi

November 2009

UNIVERSITY OF TSUKUBA

Department of Economics

1-1-1 Tennodai

Tsukuba, Ibaraki 305-8571

JAPAN 


\title{
Small Business Set-asides in Procurement Auctions: An Empirical Analysis
}

\author{
Jun NAKABAYASHI* \\ First Draft: March, 2009 \\ This Version: November, 2009
}

\begin{abstract}
As part of public procurement, many governments adopt small business programs to provide contract opportunities for businesses often with preferences for firms operated by members of groups designated as disadvantaged. The redistribution arising from such programs, however, can introduce significant added costs to government procurement budgets. In this paper, the extent to which small business set-asides increase government procurement costs is examined. The estimates employ data on Japanese public construction projects, where approximately half of the procurement budget is set aside for small and medium enterprises (SMEs). Applying a positive relationship between profitability and firm size obtained by the non-parametric estimation of asymmetric first-price auctions with affiliated private values, a counterfactual simulation is undertaken to demonstrate that approximately 40 percent of SMEs would exit the procurement market if set-asides were to be removed. Surprisingly, the resulting lack of competition would increase government procurement costs more than it would offset the production cost inefficiency.
\end{abstract}

Key words: procurement auctions, small business set-asides, structural estimation of auctions

JEL classification: D44, H23, H57, L74

\section{Introduction}

As part of public procurement, many governments adopt a program for encouraging small businesses to participate in procurement auctions. ${ }^{1}$ In the United States, the Small Business Administration suggests almost all agencies in the federal government spend an overall proportion

\footnotetext{
${ }^{*} \mathrm{PhD}$ Candidate, Department of Economics, The Ohio State University, 466 Arps Hall, 1945 North High Street, Columbus, OH 43210. Tel.: (614) 247-8489, e-mail: nakabayashi.1@osu.edu. I am grateful to Howard P. Marvel for his guidance. I also thank Hiroshi Ohashi, David Blau, Sukehiro Hosono, Mamoru Kaneko, Lung-fei Lee, Matt Lewis, and in particular, Lixin Ye for very helpful suggestions and comments. All remaining errors are my own.

${ }^{1}$ Bannock (1981) identifies the United States, Germany, Switzerland, and Japan as the countries in which governments strongly support small businesses.
} 
of 23 percent of their procurement budget with small firms. ${ }^{2}$ For some departments, such as the Department of Transportation, the expenditure for small firms in 2005 was approximately $\$ 670$ million, which accounted for 45 percent of the total annual expenditure. A similar program is seen in public procurement in Japan. For the central government, the spending target to small and medium-sized enterprises (SMEs) ${ }^{3}$ was 50.1 percent in $2007 .{ }^{4}$ As in the case of the United States federal government, the goal is achieved almost every year.

Reserving contracts to small businesses restricts competition, which can result in the market being inefficient and costly. Nevertheless, some theoretical literature of auctions predict that setasides may not hurt procurement budgets as much as had been anticipated. For instance, Ayres and Cramton (1996) investigate the affirmative action program in the FCC spectrum auctions and observe that setting aside some contracts for disadvantaged bidders enhances competition among advantaged bidders, which can compensate the efficiency loss. Milgrom (2004) points out the analog of set-asides for price discrimination conducted by a multi-market monopoly seller.

Nonetheless, the empirical literature in this field is somewhat lacking. In particular, to the best of our knowledge, there is no existing work that estimates the extent that set-asides hurt government budgets.

This paper is the first attempt to investigate the effect of set-asides on government budgets by using structural estimation techniques. In particular, the degree to which government procurement costs are changed by small business set-aside programs is quantified, and the extent to which SMEs' entry into procurement markets is promoted is also examined.

The data used in this research is from Japanese public procurement auctions for civil engineering works conducted by the Ministry of Land, Infrastructure and Transportation (MLIT), the largest procurement buyer of public works in the country. From April 2005 to March 2008, the ministry spent nearly $\$ 20$ billion $^{5}$ for approximately 11,000 civil engineering contracts, having accepted nearly 100,000 bids. The ministry set asides approximately two thirds of the

\footnotetext{
${ }^{2}$ The Federal Acquisition Regulation (FAR), Subpart 19.5. states that if the contracts are no more than $\$ 100,000$, they are automatically reserved exclusively for small business concerns and shall be set aside for small businesses.

${ }^{3}$ SMEs are defined as those that hire fewer than three hundred employees and are capitalized at equal to or less than 100 million Yen in Japan. These criteria are applied to the manufacturing, construction, and transportation industries. Service businesses and some others have slightly different criteria.

${ }^{4}$ The law "Ensuring Opportunities for Procurement of Receiving Orders from Government" encourages each ministry to employ set-asides to achieve the goal.

${ }^{5}$ It is calculated by $\$ 1=¥ 105$.
} 
procurement budget of civil engineering projects for SMEs.

Another source of data is the government database for certified contractors. It provides contractors' information about their annual sales, amounts of capital and debt, number of engineers and employees, and rate of fatal accidents. Based on the information, controls are established for firm size in the analysis in order to measure the quantitative relationship between firm size and profitability from competitive bidding processes. ${ }^{6}$

To examine the effect of a small business program on procurement costs, knowledge of what the contract prices would be should the government eliminate the program from the procurement market is necessary. However, such data are not available. Therefore, a counterfactual simulation is required to conduct comparative statics analysis of small business set-asides.

The counterfactual simulation begins by creating the competition between large firms versus SMEs. Because of set-asides, the number of sample auctions in which large firms and SMEs compete with each other is considerably limited. ${ }^{7}$ However, the size of SMEs participating differs from one to the other even in the set-aside auctions. The approach taken in this study is to regress the recovered production costs and profitabilities on firm sizes in each sample auction in order to measure the overall quantitative relationship between profitability and firm size in procurement auctions.

Therefore, our empirical analysis consists of the following three-steps. First, a procedure is used of nonparametric estimation for asymmetric first-price sealed-bid auctions with affiliated private values (APV) to identify the bidders' costs from observed bids. Then, as a second step, a regression analysis is used to find the quantitative relationship between firm size and profitability in procurement auctions, where profitability (expected payoffs) is defined by the profit margin (bid minus cost) times the probability of winning. Finally, a static entry model is constructed in which the obtained relationship between expected payoffs and firm size is employed. Regarding the estimated ex ante expected profits as a payoff from entry, the entry model predicts how many SMEs would drop out because of large firm entry into a market that was previously reserved exclusively to SMEs under the set-aside program. Furthermore, comparing the winning bid data

\footnotetext{
${ }^{6}$ The central and local governments use the information to assess whether contractors qualify for small businesses.

${ }^{7}$ Although limited, there are auctions in which large firms and SMEs compete with each other since government procurement laws do not allow contract officers to use set-asides in the case where there are too few SMEs to provide sufficient competition.
} 
with respect to the number of participants in each auction, the degree to which the resulting lack of competition affects government procurement costs is estimated.

The structural estimation technique used in this research is the nonparametric estimation of asymmetric first-price auctions with affiliated private values (APV) proposed by Campo et al. (2003). Their model relies on the assumption that the bidders' asymmetry is represented in discrete segments, such as joint bids versus single bids. The model taken here, however, considers that the asymmetry of bidders is attributed to a continuous variable, the firm size. Section 5 contains discussion of how their model should be modified if the asymmetry of bidders is not represented in the discrete segments. Following the procedure, the pseudo values of bidders' costs for each size of bidders are estimated.

The model of auctions with entry is based on a two-stage game: potential bidders decide whether to enter the first stage, and the second stage is a first-price auction. The first stage relies on the assumption that entry is sequential and the number of firms is treated as a continuous variable. As in the case of McAfee and McMillan (1987b), an assumption is made that all actual bidders must incur a fixed cost prior to bidding in order to know their own signal. In this setting, relevant estimates from the empirical analysis are used to simulate a case in which the set-aside program was to be ineffective. The virtue of the model is that the bidders' behavior in the auction game can be separated from the entry game.

Surprisingly, the estimation results suggest that the program indeed saves government procurement costs. Applying the quantitative relationship between firm size and productivity to the average difference in firm size between large firms and SMEs, on average, the production cost of SMEs is 1.2 percent higher than that of large firms. Similarly, based on the quantitative relationship between firm size and winning frequency, an SME would win 5.2 percent less frequently than a large firm if an SME and a large firm competed one-on-one. These small differences in costs and winning probability lead to a non-trivial difference in profitability between the two groups of bidders. The expected payoff of an SME would be 43 percent lower than that of a large firm when both compete in the same auction. The simulation result indicates that, due to the disadvantage in profitability, the participation of SMEs would drop by 38 percent on average were set-asides to be removed. Consequently, the large firms' shifting their entry to originally set-aside projects would cause the following two competing effects on procurement 
costs. The prices of the originally set-aside projects would fall due to the entry by cost-efficient large firms, whereas the prices of the related projects that would have been reserved exclusively to SMEs under the set-aside program would rise because of an approximately 43 percent decline in the number of large firms. The simulation studies suggest that the latter effect dominates the former in our simulation so that the program should decrease the procurement costs by 0.28 percent.

The empirical results conclude that the set-aside program has been successful. It improves equity between advantaged and disadvantaged firms without substantial increase of procurement costs. The results not only correspond to the prediction by the theoretical literature on asymmetric auctions but also are in line with the seminal empirical work of Denes (1997) on set-aside programs, despite the difference in approach and data. In addition, our structural estimation further illustrates that the subsidized SMEs drive non-subsidized bidders to give up more of the gain on the contracts they award. The large firms' expected net gain is almost zero while it would be 1.82 percent of the estimated project cost without the small business program. In other words, set-asides squeeze more rents from large firms, which enables the procurement buyer to lower procurement costs more than offsetting the resulting production cost inefficiency.

The remainder of this paper is organized as follows. Section 2 addresses the related literature. Section 3 provides a brief explanation on public construction procurement markets in Japan. Section 4 is a description of the data. A theoretical model of asymmetric first-price sealed-bid auctions is provided in section 5. Section 6 is a description of the theoretical and empirical models about auctions with endogenous participation. Section 7 is a illustrates the estimation and simulation results. Section 8 is a presentation of the discussion. The final section contains further discussion and the conclusion. The proofs are given in the Appendix.

\section{Related literature}

Ayres and Cramton (1996) investigate the affirmative action program in United States FCC spectrum auctions. Their case studies focus on the "regional narrowband" auctions of thirty licences for use in advanced paging service. In the FCC's affirmative action, disadvantaged bidders, such as small businesses and woman or minority owned firms, are granted a 40 percent 
bidding credit on ten of the thirty narrowband licenses, as well as a subsidy for their interest payments. Since the combination effect is that favored bidders had to pay the government only 50 percent of a winning bid, they consider that the credit is large enough to discourage entry by advantaged firms. Surprisingly, their estimation suggests that this effective set-aside program increases the government's revenues by approximately $\$ 45$ million, or 12 percent of the government's total auction revenue. They also note that set-aside auctions are able to raise the expected auctioneer's welfare if 1) there is insufficient competition among strong bidders; 2) the seller is able to identify who is strong or weak; 3) resale is prohibited.

Denes (1997) provides the first thorough analysis for the impact of small business set-asides in public procurement. He investigates the federal dredging contracts during 1990 and 1991 and examines the mean values of set-aside (or restricted) bids compared with the mean values of the unrestricted bids on the data in eight categories and performs a series of paired $t$-tests. He finds that in all but one instance, there is no significant difference between the bids submitted for set-asides and the bids submitted on unrestricted solicitations and concludes that there is no evidence to suggest that set-asides are costly. According to his study, 3.6 firms bid on the set-asides, whereas only 3.1 firms bid when set-asides were not employed, which, he suggests, induces either no change or a lower bid price on the set-asides.

Marion (2007) provided the first systematic analysis for affirmative action in the public procurement. He investigated the effect of the bidding credit program in highway procurement auctions by the California Department of Transportation. Then, he argued that by granting a bid preference to higher-cost bidders, the government loses surplus from lower-cost bidders by awarding contracts to likely higher-cost competitors. At the same time, the preferential treatment increases the competitive pressure exerted by favored bidders. In descriptive regressions, he found that the auctions with bidding credits increase procurement costs by 3.5 percent, possibly because the likelihood of large firm participation is smaller for preference auctions than for non-preference auctions.

Finally, Athey and Levin (2006) examine the small business set-asides in the United States Forest Service timber auctions. They found that set-asides exclude a substantial number of advantaged bidders, whereas, there was no evidence that government revenue falls significantly (3 percent). Their analysis also indicates that the efficiency loss caused by the participation 
restriction is approximately 4 percent for an average sale, which is not considered to be significant for the total amount of the government income.

\section{Public construction markets in Japan}

\subsection{Overview}

Investment in the construction industry accounts for nearly 20 percent of the country's GDP and employs more than 10 percent of the working population in Japan. The percentage of public investment as a portion of all construction investment was 45.6 in 2001.

Public account law requires that all government and public entities practice competitive bidding when they acquire construction works exceeding 2.5 million Yen. Three types of bidding systems are used in the public sector: 1) open competitive bidding, 2) invited bidders, and 3) contract at discretion. Although not a majority, scoring tenders are also used in the awarding mechanism, in which bidders submit not only the price but also another variable, such as the term of work or quality of work.

An idiosyncratic feature of the Japanese public procurement system is in the screening process for bidders. Contractors must take a preliminary qualification exam in order to bid for projects. The exam measures a firm's technological, financial, and geographical status and gives them scores as a result of the evaluation. For each auction, the procurer selects, or makes an announcement to, a set of legislated contractors as qualified bidders, and the selection is based on the exam results.

In procurement auctions, governments face the risk of awarding the contract to less-qualified or inferior firms that might default. Some projects demand advanced technologies and skills, as well as a sufficient amount of capital to complete. ${ }^{8}$ To mitigate such an asymmetric information problem, screening processes for selecting qualified bidders are essential to the success of the auction. ${ }^{9}$ The preliminary qualification exam works in the same manner as the bonding system in the United States public construction market. A brief discussion of the preliminary qualification

\footnotetext{
${ }^{8}$ The possibility of default or non-performance can have perverse effects on the bidding in an auction; a bidder with a high likelihood of default tends to be chosen as a winning bidder. See Zheng (2001) for more details.

${ }^{9}$ See also Bajari and Tadelis (2001) and Laffont and Tirole (1994) for more discussion on the importance of the screening processes in procurement auctions.
} 
examination in Japan is presented in the next section.

Another major difference in the Japanese procurement system is in the contract principle. Unlike in the United States and many other countries, construction contracts are based on total price contracts, in which bidders submit only a total price without necessarily itemizing unit prices. Instead, engineering offices regularly update market price lists and use them in the event that a change order is called for during a certain performance. The yearly updates on these price lists are based on hearing investigation, but the survey is conducted independently from procurement auctions. Unfortunately, there is no formal theory that analyzes the effect of contract formats on bidding behaviors. Therefore, the empirical analysis here ignores the contract format effect.

Finally, the announcement policy of the reservation price and engineer's estimated costs differs from that of many other countries, in which these are typically opened prior to bidding in auctions. On the other hand, in most public procurement auctions in Japan, such information is secret until the auction is over. However, the secrecy of the reservation price is mitigated with the auction design. If no bid is below the reservation price, the next round auction begins immediately with the same member. This process goes on at most three times. The project is reserved unless any contractor bids below the reservation price at the third round. In this sense, reservation prices are not binding in the first round.

\subsection{Preliminary qualification examination}

Preliminary qualification certifies a set of firms as bona fide bidders in procurement auctions to protect the owner of a project against the risk of non-performance. Similar screening processes are widely used at public procurement auctions in Europe and work in the same manner as the bonding system in the United State public construction auctions in terms of reducing the risk of contractor's default.

The preliminary qualification in Japan is based on the firm's disclosure of information with respect to their financial and technological performance. In particular, information includes annual sales, number of engineers in each area of expertise, experience, and business history. Based on the set of information as well as the evaluation of work performed, governments measure the firm's overall ability to perform. As a result of this evaluation, the qualified firms 
typically obtain two kinds of scores for each area of their expertise.

The first score is called the "Business Evaluation" (BE) score, which is essentially a weighted average of 1) the annual value of completed construction works by license classification, 2) the number of technical staff, 3) the business conditions (based on financial statement analysis), 4) the number of engineers, and 5) the record of safety performance. For the qualified bidders of MLIT, the maximum and minimum scores are 1859 and 329, respectively, with an average of 851.1. The detailed summary statistics on Business Evaluation are available in Section 4. The $\mathrm{BE}$ score is given through the countrywide criteria of measurement specified in construction industry law; thus, each firm has a unique score value for each expertise. ${ }^{10}$

The assessment on whether a firm is favored in the set-aside program is based on the BE scores. 11 Following this fact, the BE scores is used to control for the corporation size in our analysis.

\subsection{Set-asides in the public construction market}

The selection rule for bidders is primarily based on the "size matching rule." When a particular project is auctioned, a set of bidders is chosen so that their sizes will match the project size. For instance, only large firms are qualified to participate in the auctions for large and highend projects and are not allowed to bid on small and low-end projects, which are reserved for SMEs. ${ }^{12}$ The size-matching rule has priority in the selection of bidders unless the number of designated bidders is too small to provide adequate competition.

Set-asides are the only explicit method to favor SMEs in Japanese public procurement auctions. Every year, the Japanese central and local governments determine the objective set-aside budgets by which the governments should assign contracts to SMEs. ${ }^{13}$ In 2005 , central govern-

\footnotetext{
${ }^{10}$ The number of expertise is 28 , which is specified in the construction industry law. Firms must obtain a license for each area of expertise to operate.

${ }^{11}$ More precisely, governments assign grade for each firm based on the total score. For instance, MLIT gives either "A", "B", "C", or "D" for each certified contractor with civil engineering expertise, where A is the highest grade. Large contractors are likely to receive " $\mathrm{B}$ " or higher and are likely to receive a grade of "A" if the firm is operated countrywide. Based on the grade, governments implement the set-aside program in such a way that a firm with a grade of A or B is excluded from bidding for low-end projects.

${ }^{12}$ Set-asides are implemented as part of the size-matching rule. In the case of MLIT, it also grades every civil engineering work from A to D according to the size, where grade A is the highest-end. Engineer's estimated costs are typically used as a proxy to determine the project size. Under the size-matching rule, contractors are selected or allowed to participate in the auction so that their grades match the project grade.

${ }^{13}$ This policy is specified by the "Law on ensuring the receipt of orders from small and medium enterprises."
} 
ments and public entities spent $¥ 8.8$ trillion to purchase land and items, construction works, and services. $¥ 4.1$ trillion was expended to SMEs, which accounted for 46.9 percent of the total budget (the target amount was $¥ 4.3$ trillion, accounting for 46.7 percent). For the Ministry of Land, Infrastructure and Transportation, 50.8 percent of the entire expenses was allocated to SMEs in the year. To achieve the goal, approximately two thirds of civil engineering contracts were set aside for SMEs.

\section{The data}

\subsection{Overview}

The data used in the analysis contains the bid results of the procurement auctions for civil engineering projects from April 2005 through March 2008. The number of contracts awarded was 11,114 during this period.

MLIT posts the bid results on the website, Public works Procurement Information service (PPI). ${ }^{14}$ The information available in PPI includes the name of orderers (local branch name), project names, project types, date of auctions, reservation prices, auction formats (open competitive bidding or invited bidders), and submitted bids with the bidder's name. ${ }^{15}$ PPI also provides the lists of all qualified firms, which consist of the address of the firm's headquarters, the name of owner, business evaluation scores as well as grades for each area of expertise. All the data in this empirical study is from the website.

MLIT procures 21 types of construction works including civil engineering (or heavy and general construction works), buildings, bridges, paving, dredging, and painting. The amount of civil engineering projects is approximately $¥ 750$ billion a year, which accounts for approximately 54 percent of the entire expenditure of the ministry as indicated in Figure 1 and 2 as well as for 7 percent of the public construction investment in the country.

MLIT has 9 regional development divisions in 9 regional districts. The data includes the civil engineering projects in 8 districts indicated in Figure 1. Each of the regional development divisions has a certified firms' list from which it chooses the bidders for each procurement

\footnotetext{
${ }^{14}$ The address is "http//www.ppi.go.jp."

${ }^{15}$ The information concerning work location is not generally available.
} 
auction. The lists are updated every two years. The total number of firms on the lists was 43,522 in April 2007. Since large firms typically operate across several regions, it is often the case that a particular firm is listed on two or more of these lists. The number of firms without such duplication is 32,993 , which accounts for approximately 20 percent of all the licensed civil engineering construction firms in Japan. ${ }^{16}$

The data has some limitation in the identification of contractors. The bid results provides the bidder's company name only. Therefore, in the case that two or more different firms have an identical company name, the bidder's identity can be guessed but not ensured. ${ }^{17}$ The way to narrow down the candidate list is on the basis that whether i) the location (prefecture) of the project matches the location of headquarters, and ii) the bidder's size matches the project size according to the size-matching rule. Through this process, almost all contractors on the bid results is identified. The remaining unidentified firms in the auction are assumed to be the average sized firm in the auction.

\subsection{Summary statistics of bids and scores}

\subsubsection{Normalization of the bidder's size}

In the observations, each auction has a unique set of bidders in general. Hence, a firm with a higher score can be a smaller bidder if the opponents have a much higher score and vice versa. To model the firm's size in comparison to the size of its opponents, the Business Evaluation score is normalized (hereafter, normalized score) in the following procedure.

Let as assume that there are $m$ auctions and the number of bidders in auction $k=1, \ldots, m$ is denoted by $n_{k}$. Let $X_{i, k}$ be the value of the Business Evaluation score of the $i$ th lowest bidder in auction $k .^{18}$

None of the bidders is informed of who the competitors are. In fact, however, the bidders may speculate about their competition based upon the project location, project size, and the competitor's backlog. Hence, the stylized model used here assumes that the $i$ th bidder in the

\footnotetext{
${ }^{16}$ The total number of licensed civil engineering firms is 167,896 in 2005 (MLIT, 2005).

${ }^{17}$ For example, there are seven "Showa Kensetsu Co., Ltd" on the contractor list of Kanto District Development Bureau. The bid results do not indicate which "Showa Kensetsu" in fact bid.

${ }^{18}$ Note that the analysis assumes that the bidders' asymmetry comes from their size, all the information with respect to the bidder's identity in the observation is discarded except the relative size.
} 
$k$ th auction knows the average score of the opponent bidder $\bar{X}_{-i, k}=\sum_{j \neq i} X_{j, k} /\left(n_{k}-1\right)$, but not for each $X_{j, k}$.

If follows that the mean score $\bar{X}_{k}$ in the $k$ th auction is known to each bidder by calculating $\bar{X}_{k}=\frac{\left(n_{k}-1\right) \bar{X}_{-i, k}+X_{i, k}}{n_{k}}$. The normalized score is then calculated as,

$$
x_{i, k}=\frac{X_{i, k}-\bar{X}_{k}}{\bar{X}_{k}} .
$$

Because of the assumption for $\bar{X}_{-i, k}$, the value $x_{i, k}$ not only represents the relative size of the $i$ th bidder in auction $k$ but also informs the $i$ th bidder about the average relative size of his opponents. For instance, $E\left[x_{j, k} \mid x_{i, k}\right]$ will be negative for any $j$ if and only if $x_{i, k}$ is positive. ${ }^{19}$

Table 3 provides the summary statistics on $X_{i, k}$ and $x_{i, k}$ of the actual bidders. Figure 2 depicts the histogram for the normalized score. The effect of the set-aside program is glimpsed from the fact that the coefficient of variation $(\mathrm{CV})$ on $X_{i, k}$, which is defined by the standard deviation divided by the mean of $X_{i, k}$, is approximately 13 percent. Therefore, if bidders are randomly picked in each auction, the standard deviation of $x_{i, t}$ would be 13 percent. However, the actual standard deviation is 7.6 percent, which suggests that the participation restriction by government reduces the asymmetry of bidders.

\subsubsection{Percentage bids}

Figure 3 contains a description of the histogram on the project size. Since each construction project is unique, there remains a great deal of heterogeneity in project size. The most typical contract is for approximately $¥ 100$ million measured in the engineer’s estimated costs. The largest is approximately $¥ 12$ billion, while the smallest is less than $¥ 1$ million. Table 4 is a breakdown of the summary statistics of project size.

To eliminate the project heterogeneity, all bids in the empirical analysis are described by the percentage with respect to the engineer's estimated cost. If the $k$ th auction is the price-only auction, then the percentage bid of the $i$ th lowest bid is given by

$$
\frac{\operatorname{Bid}_{i, k}}{\operatorname{Est}_{k}}
$$

\footnotetext{
${ }^{19}$ This is because $\sum_{\tau \neq i} x_{\tau, k}+x_{i, k}=0$ in my model.
} 
where $\operatorname{Bid}_{i, k}$ is the value of the $i$ th lowest bid and Est $k$ is the engineer's estimated cost for auction $k$. If the $k$ th auction is a scoring auction in which bidders submit not only the price bid but also some other factors, such as quality and completion time, then the bidder with the highest score wins the project. Therefore, percentage bids for a scoring auction are defined by Basescore $_{k} /$ Scorebid $_{i, k}$, where the "Basescore" is the score in which the price-bid is equal to the engineer's estimated cost and nothing is evaluated as the factor bid.

\subsubsection{Regression results for bids on corporate size}

It is evident that, in each auction, larger firms bid lower prices than smaller ones. Table 5 contains a description of the result of regression for the percentage bids on normalized scores. Auction-specific effects are taken into account by fixed-effect and random-effect models. After dropping 306 out of 11,375 auctions, which contain "throw-away bids" i.e., larger than 200 percent of the engineer's estimated cost, the negative relationship between the normalized bids and size is significant ( $t$-value : 6.03 in FE estimation). ${ }^{20}$ The number of observations after exclusion equals 86,798. Figure 4 shows that the bid density of larger firms (the score is 10 percent greater than the average) is shifted downward when compared to that of smaller firms (the score is 10 percent smaller than the average). Table 5 indicates that the bidder's size yields a small but statistically significant difference in bids.

Finally, the production capacity utilization is explored in procurement auctions. Figures 5 and 6 illustrate that many small businesses on the lists have little opportunity to bid in spite of the set-aside program. Figure 5 depicts the density on the Business Evaluation score of the bidders who actually bid, while Figure 6 shows the score of all the firms on the certified contractor lists. The density shifting toward the left in figure 6 indicates that, despite the small business set-asides, a sufficient volume of production capacity remains available in small businesses.

\footnotetext{
${ }^{20}$ The exclusion of extremely high bids was also conducted in Corns and Schotter (1999). They mentioned that these observations have to be removed from the sample because of the influence they would have on the estimation.
} 


\section{Recovery of the bidders' cost distribution}

\subsection{Overview}

Our nonparametric estimation of first-price sealed-bid auctions is based on Campo et al. (2003), which is an extension of Guerre et al. (2000) to cases with asymmetric bidders with the APV model. The approach of Campo et al. (2003) relies on the assumption that the bidder's asymmetry is represented by a finite number of segments. Hence, if the number of segments is equal to $d$, a $(d+1)$-dimensional kernel estimation is required. Therefore, if an empirical model assumes that the bidder's asymmetry is attributed to a continuous variable, then kernel estimation cannot hold.

More recently, Zhang and Guler (2005) proposed a simplified approach in which the only requirement is a two-dimensional kernel estimation regardless of the structure of bidder asymmetries. The essence of their approach is to estimate the bidder's signal separately for each bidder, expressing each bidder's payoff function in terms of the equilibrium distribution of rival bids. They claim that one can avoid suffering from the dimensionality of kernels as long as the set of bidders in the sample is identical. Unfortunately, their approach causes another problem if the data involves heterogeneity in the set of participants across auctions, as it does in this case.

Hence, a model of asymmetric auctions is reconstructed to utilize more samples in kernel estimation. In particular, each bidder is assumed to know his own strength (normalized score) but has limited information about his competitors'. As shown in the next subsection, the bidders are still ex ante asymmetric on this assumption. Furthermore, this assumption is more realistic in actual procurement auctions, in which the participants are endogenously determined and nobody knows who the actual opponents are upon bidding.

\section{$5.2 \quad$ A model of asymmetric auctions}

A single and indivisible project is auctioned to $n$ risk-neutral bidders. There is an $n$-dimensional distribution with a cumulative distribution function $H(\cdot)$. The vector of each bidder's normalized score $x \equiv\left(x_{1}, \ldots, x_{n}\right)$ is a realization of a random vector with a joint distribution $H(\cdot)$. Let

us assume that $H(\cdot)$, and $n$ are common knowledge. Then, for each $i \in \mathcal{N} \equiv\{1, \ldots, n\}$, 
the conditional distribution of $x_{-i} \equiv\left(x_{1}, \ldots, x_{i-1}, x_{i+1}, \ldots, x_{n}\right)$ and its density are denoted by $H_{-x_{i} \mid x_{i}}\left(x_{-i} \mid x_{i}\right)$ and $h_{-x_{i} \mid x_{i}}\left(x_{-i} \mid x_{i}\right)$, respectively. Let us assume that, for all $i, H_{-x_{i} \mid x_{i}}\left(x_{-i} \mid x_{i}\right)$ has support $[\underline{x}, \bar{x}]^{n-1}$ and that the probability density function $h_{-x_{i} \mid x_{i}}\left(x_{-i} \mid x_{i}\right)$ is continuous in $x_{-i}$.

The asymmetric APV model with risk-neutral bidders is defined by an $n$-dimensional distribution with a cumulative distribution function $F(\cdot \mid x)$. The vector of private information $\left(c_{1}, \ldots, c_{n}\right)$ is a realization of a random vector with joint distribution $F(\cdot \mid x)$. The asymmetry of bidders is captured by $x$ such that $x_{i}$ affects the marginal distribution of $c_{i}$ but not the distribution of $c_{j}$ for any $j \in \mathcal{N} \backslash\{i\}$. In other words, the marginal distribution of $c_{i}$ is represented by $F_{c_{i}}\left(c_{i} \mid x_{i}\right)$ for all $i \in \mathcal{N}$. The affiliation is captured as follows: let us assume that the $i$ th bidder's signal is $c_{i}$, then for some $j$, the marginal distribution of $c_{j}$ and its density are given by $F_{c_{j} \mid c_{i}}\left(c_{j} \mid c_{i}, x_{j}\right)$ and $f_{c_{j} \mid c_{i}}\left(c_{j} \mid c_{i}, x_{j}\right)$.

Using $b_{i}=\beta\left(c_{i} \mid x_{i}\right)$ and $\theta\left(b_{i} \mid x_{i}\right)=\beta^{-1}\left(b_{i} \mid x_{i}\right)$, let us denote the equilibrium bidding strategy and its inverse, respectively. In equilibrium, the joint distribution of valuations $F(\cdot \mid x)$ and the distribution of bids $G(\cdot \mid x)$ are related with $G\left(b_{1}, \ldots, b_{n} \mid x\right)=F\left(\theta\left(b_{1} \mid x_{1}\right), \ldots, \theta\left(b_{n} \mid x_{n}\right) \mid x\right)$. Let us assume that the marginal distribution of $\operatorname{costs} F_{c_{j} \mid c_{i}}\left(c_{j} \mid c_{i}, x_{j}\right)$ has support $[\underline{c}, \bar{c}]$ for any $i$ and $j$ and that the probability density function $f_{c_{j} \mid c_{i}}\left(c_{j} \mid c_{i}, x_{j}\right)$ is continuously differentiable (in $c_{j}$ ). Finally, let us assume that for all $i \neq j, f_{c_{j} \mid c_{i}}\left(\cdot \mid c_{i}, x_{j}\right)$ is bounded away from zero on $[\underline{c}, \bar{c}]$. Then, firm $i$ 's conditional payoff can be written as

$$
\pi\left(b_{i} \mid c_{i}, x_{i}\right)=\max _{b_{i}}\left(b_{i}-c_{i}\right) \operatorname{Pr}\left\{b_{i} \leq B_{i} \mid c_{i}, x_{i}\right\}
$$

where $B_{i}$ is bidder $i$ 's minimum rival bid, namely $B_{i} \equiv \min \left\{b_{1}, \ldots, b_{i-1}, b_{i+1}, \ldots, b_{n}\right\}$.

Then, an increasing Bayesian-Nash equilibrium is considered in pure strategies. An equilibrium in pure strategies is an $n$-dimensional strategy profile $\left(\beta\left(\cdot \mid x_{1}\right), \ldots, \beta\left(\cdot \mid x_{n}\right)\right)$ such that $\beta(\cdot)$ maximizes $\pi\left(b_{i} \mid c_{i}, x_{i}\right)$ in $b_{i}$ for all $i$, and $c_{i}$ in its support.

Let us assume that there exists an increasing equilibrium such that each firm $i$ bids according to a strictly increasing function $\beta\left(c_{i} \mid x_{i}\right)$. Then, for any $i \in \mathcal{N}$ and $j \in \mathcal{N} \backslash\{i\}, G_{b \mid b_{i}}\left(b_{j} \mid b_{i}, x_{i}, x_{j}\right) \equiv$ $F_{c_{j} \mid c_{i}}\left(\theta\left(b \mid x_{j}\right) \mid \theta\left(b_{i} \mid x_{i}\right), x_{j}\right)$ is defined as the probability with which $b_{j}$ is equal to or greater than $b$ given $b_{i}$ and $x$. Note that $G_{b_{j} \mid b_{i}}(\cdot)$ satisfies the property of probability distribution since $\beta(\cdot)$ 
is strictly increasing.

For the $i$ th bidder, the minimum rival bid $B_{i}$ is a random variable conditional on $b_{i}$ and $x_{i}$. Therefore, $G_{B_{i} \mid b_{i}}\left(B_{i} \mid b_{i}, x_{i}\right)$ is used to denote the conditional cumulative distribution of $B_{i}{ }^{21}$ Then, the bidder $i$ 's winning probability $1-G_{B_{i} \mid b_{i}}(\cdot)$ is given by

$$
1-G_{B_{i} \mid b_{i}}\left(b_{i} \mid b_{i}, x_{i}, x_{-i}\right)=\prod_{j \in \mathcal{N} \backslash\{i\}}\left\{1-G_{b_{j} \mid b_{i}}\left(b_{i} \mid b_{i}, x_{i}, x_{j}\right)\right\}
$$

given that other bidders follow $\beta(\cdot)$. Note that $G_{B_{i} \mid b_{i}}$ is strictly increasing. Since the bidder $i$ does not know $x_{-i}$, the bidder $i$ 's expected winning probability, $1-\bar{G}_{B_{i} \mid b_{i}}(\cdot)$, is thus given by ${ }^{22}$

$$
1-\bar{G}_{B_{i} \mid b_{i}}\left(b_{i} \mid b_{i}, x_{i}\right)=\int_{x_{-i}}\left[1-G_{B_{i} \mid b_{i}}\left(b_{i} \mid b_{i}, x_{i}, x_{-i}\right)\right] h_{x_{-i} \mid x_{i}}\left(x_{-i} \mid x_{i}\right) d x_{-i}
$$

Then, the $i$ th bidder's maximization problem becomes

$$
\pi\left(b_{i} \mid c_{i}, x_{i}\right)=\max _{b_{i}}\left(b_{i}-c_{i}\right)\left[1-\bar{G}_{B_{i} \mid b_{i}}\left(b_{i} \mid b_{i}, x_{i}\right)\right]
$$

given that other bidders follow $\beta\left(\cdot \mid x_{j}\right)$. Then, the $i$ th bidder's first order condition gives

$$
c_{i}=b_{i}-\frac{1-\bar{G}_{B_{i} \mid b_{i}}\left(b_{i} \mid b_{i}, x_{i}\right)}{\bar{g}_{B_{i} \mid b_{i}}\left(b_{i} \mid b_{i}, x_{i}\right)},
$$

where $\bar{g}_{B_{i} \mid b_{i}}(\cdot)$ is the density of $\bar{G}_{B_{i} \mid b_{i}}(\cdot)$.

The right-hand side of (2) gives a unique inverse bid function $\theta\left(b_{i} \mid x_{i}\right)$. It implies that $i$ 's strategy is also represented by $\beta\left(b_{i} \mid x_{i}\right)$. Hence, it is a Bayesian-Nash equilibrium in asymmetric first-price auctions with APV. The bidding function can be obtained by solving the system of differential equation represented by $\theta\left(b_{i} \mid x_{i}\right)$ for all $i$.

\footnotetext{
${ }^{21}$ By affiliation of $c, b_{i}$ influences $G_{B_{i} \mid b_{i}}$, while, by heterogeneous distribution of $c, x_{i}$ affects $G_{B_{i} \mid b_{i}}$.

${ }^{22}$ The right-hand side is more formally expressed as

$$
\int_{x_{1}} \ldots \int_{x_{i-1}} \int_{x_{i+1}} \ldots \int_{x_{n}}\left[1-G_{B_{i} \mid b_{i}}\left(b_{i} \mid b_{i}, x_{1}, \ldots, x_{i-1}, x_{i+1}, \ldots, x_{n}\right)\right] h_{-x_{i} \mid x_{i}}\left(x_{1}, \ldots, x_{i-1}, x_{i+1}, \ldots, x_{n} \mid x_{i}\right) d x_{1} \ldots d x_{i-1} d x_{i+1} \ldots d x_{n} .
$$
}




\subsection{Nonparametric estimation}

Campo et al. (2003) show that the latent value $c_{i}$ can be estimated by using the inverse bid function $\theta(\cdot)$. They show that the estimator for costs can be obtained by computing the bid distribution $\bar{G}_{B_{i} \mid b_{i}}$ and its density $\bar{g}_{B_{i} \mid b_{i}}$ without solving the system of differential equations.

As in Zhang and Guler (2005), the first step is to interpret (2). By definition, $1-G_{B_{i} \mid b_{i}}\left(b_{i} \mid b_{i}, x_{i}\right)$ is the probability that the minimum rival bid $B_{i}$ is greater than $b_{i}$ conditional on $b_{i}$. Moreover, $\bar{g}_{B_{i} \mid b_{i}}\left(b_{i} \mid b_{i}, x_{i}\right)$ is the derivative of $\bar{G}_{B_{i} \mid b_{i}}(\cdot)$. Hence, (2) can be rewritten as

$$
c_{i}=b_{i}-\frac{\operatorname{Pr}\left(b_{i}<B_{i} \mid b_{i}, x_{i}\right)}{\operatorname{Pr}\left(b_{i}=B_{i} \mid b_{i}, x_{i}\right)}
$$

For estimation, let us assume that there are $k=1, \ldots, m$ auctions and that $n$ bidders bid in each. Then, let $B_{i, k}=\min _{j \neq i} b_{j, k}$ denote the $i$ 's minimum rival bid for any sample auction $k$. Unlike the standard estimation model, the assumption that the set of bidders in each sample is the same is relaxed. In other words, the $i$ th bidder in the $k$ th auction can be different from the $i$ th bidder in the $k^{\prime}$ auction. Thus, the number of combinations of $x_{k} \equiv\left(x_{1, k}, \ldots, x_{n, k}\right)$ in the observations is infinitely large.

However, the problem can be easily solved using the fact that $\bar{G}_{B_{i} \mid b_{i}}$ and $\bar{g}_{B_{i} \mid b_{i}}$ depend only on $x_{i}$; to know the latent value of the $i$ th bidder in the $k$ th auction, the values of the $j$ th bid in the $k^{\prime}$ th auction can be used if the counterpart bidder's score $x_{j, k^{\prime}}$ is the same or close enough to $x_{i, k}$.

The numerator and denominator in the ratio of inverse bid functions are thus given by

$$
\left\{\begin{array}{l}
\operatorname{Pr}\left(b \leq B \mid b_{i, k}, x_{i, k}\right)=\frac{1}{m h_{G} h_{x}} \sum_{l=1}^{m} \sum_{\tau=1}^{n} \mathbf{1}\left(b \leq B_{\tau, l}\right) K_{G}\left(\frac{b-b_{\tau, l}}{h_{G}} \frac{x_{i, k}-x_{\tau, l}}{h_{x}}\right), \\
\operatorname{Pr}\left(b=B \mid b_{i, k}, x_{i, k}\right)=\frac{1}{m h_{g}^{2} h_{x}} \sum_{l=1}^{m} \sum_{\tau=1}^{n} K_{g}\left(\frac{b-B_{\tau, l}}{h_{g}}, \frac{b-b_{\tau, l}}{h_{g}}, \frac{x_{i, k}-x_{\tau, l}}{h_{x}}\right) .
\end{array}\right.
$$

These hold to the extent that the number of bidders is identical in the sample and there is no heterogeneity in the characteristics of projects. In fact, the observations in the paper involve significant heterogeneity in the number of bidders and the characteristics, such as location, project size, and auction date. The next subsection is an explanation of how to control for heterogeneity. 


\subsubsection{Heterogeneity}

Here, we essentially follow Guerre et al. (2000) to control the heterogeneity in the number of bidders and the characteristics of each auction. Guerre et al. (2000) report that these are tractable in nonparametric identification by introducing additional dimensions on kernels. The data taken here involve considerable heterogeneity in both the number of bidders ${ }^{23}$ and the auction format (menu auctions or price only auctions). The procedure is described as follows.

Let $z_{k}$ denote the vector of associated characteristics in project $k$. Let us assume that the bidders' cost distribution for the $k$ th auction is given by the conditional distribution $F\left(\cdot \mid z_{k}\right)$ for some $z_{k}$. Then, the distribution of observed bids in auction $k$ is given by $G\left(\cdot \mid n_{k}, z_{k}\right)$. Hence, (2) is rewritten as

$$
c_{i, k}=b_{i, k}-\frac{1-\bar{G}_{B_{i, k} \mid b_{i, k}}\left(b_{i, k} \mid b_{i, k}, x_{i, k}, n_{k}, z_{k}\right)}{\bar{g}_{B_{i, k} \mid b_{i, k}}\left(b_{i, k} \mid b_{i, k}, x_{i, k}, n_{k}, z_{k}\right)} .
$$

Hence, (3) becomes

$$
\left\{\begin{array}{c}
1-\bar{G}_{B_{i, k} \mid b_{i, k}}\left(b \mid b_{i, k}, x_{i, k}, z_{k}, n_{k}\right) \\
=\frac{1}{m h_{G}^{i, k} h_{x}^{i, k} h_{n}^{k} h_{z}^{k}} \sum_{l=1}^{m} \frac{1}{n_{l}} \sum_{\tau=1}^{n_{l}} \mathbf{1}\left(b \leq B_{\tau, l}\right) K_{G}\left(\frac{b-b_{\tau, l}}{h_{G}^{i, k}}, \frac{x_{i, k}-x_{\tau, l} l}{h_{x}^{i, k}}, \frac{n_{k}-n_{l}}{h_{n}^{k}}, \frac{z_{k}-z_{l}}{h_{z}^{k}}\right), \\
\bar{g}_{B_{i, k} \mid b_{i, k}}\left(b \mid b_{i, k}, x_{i, k}, z_{k}, n_{k}\right) \\
=\frac{1}{m\left(h_{g}^{i, k}\right)^{2} h_{x}^{i, k} h_{n}^{k} h_{z}^{k}} \sum_{l=1}^{m} \frac{1}{n_{l}} \sum_{\tau=1}^{n_{l}} K_{g}\left(\frac{b-B_{\tau, l}}{h_{g}^{i, k}}, \frac{b-b_{\tau, l}}{h_{g}^{i, k}}, \frac{x_{i, k}-x_{\tau, l}}{h_{x}^{i, k}}, \frac{n_{k}-n_{l}}{h_{n}^{k}}, \frac{z_{k}-z_{l}}{h_{z}^{k}}\right),
\end{array}\right.
$$

where $K_{G}$ is a four-dimensional kernel and $K_{g}$ is a five-dimensional kernel. The regularity assumption for $F$ and $G$ is provided in Guerre et al. (2000).

Since our model relaxes the assumption that each auction must have the same sample bidders, the $h_{g}$ and $h_{G}$ are essentially different for each bidder in the different auction. As usual, the bandwidth is given by $h_{g}=c_{g}\left(\sum_{k=1}^{m} n_{l}\right)^{-1 / 6}$ and $h_{G}=c_{G}\left(\sum_{k=1}^{m} n_{l}\right)^{-1 / 5}$, where $c_{G}=c_{g}=$ $2.978 \times 1.06 \hat{\sigma}_{b}$ by the so-called rule of thumb. The following triweight kernel is used in the nonparametric identification:

$$
K(u)=\frac{35}{32}\left(1-u^{2}\right)^{3} \mathbf{1}(|u|<1) .
$$

\footnotetext{
${ }^{23}$ The smallest number is two and the largest 53 .
} 
The calculation is executed using a program written in $\mathrm{C}++$ and takes approximately an hour to obtain 100 thousand latent variables.

The informational rent decreases as the number of bidders increases. Figure 7 shows the bidding function in the case of a small number of participants ( 5 bidders), and Figure 8 describes the case of many participants (between 22 and 28 bidders). In both figures, the dark plots represent the bidding function and the light plots represent the 45-degree line. The bid margins are larger in the case of a smaller number of competitors.

Table 5 shows the regression result for the estimated costs as a function of a firm's size. Again, the fixed and random effects control for the auction-specific heterogeneity, and all the throw-away bids (greater than 200 percent of the reservation price) are dropped in the regression. Table 5 suggests the statistical significance (t-value : 6.99 in FE regression) that large firms have a cost advantage.

Literature on asymmetric first-price auctions predicts that disadvantaged bidders bid more aggressively than advantaged bidders in an auction. Table 6 shows the regression result of a log bid margin (a submitted bid minus the estimated cost) on bidders' relative sizes. It is statistically significant (t-value : 6.22 in the fixed-effect regression) that a smaller bidder in an auction is likely to bid with a thinner margin than a larger bidder.

\section{$6 \quad$ A model for auctions with entry}

Our stylized entry model considers that a government procures only two projects, high-end, denoted by $H$, and low-end, denoted by $L$. There are two groups of firms, large ones, denoted by $L B$, and SMEs, denoted by $S B$. Let us assume that every firm has a unit production capacity regardless of its size. Based on the fact observed at the end of Subsection 4.2.3, the number of large firms is assumed to be limited to a finite number $n_{L B}$, whereas there is an infinitely large number of SMEs. Furthermore, let us assume that project $H$ is so technologically demanding that SMEs are not allowed to bid. The two projects are auctioned through two independent first-price sealed-bid auctions that take place simultaneously.

The procurement proceeds in the following two-stage game: potential bidders decide their entry in the first stage and auctions take place in the second stage. Once a potential bidder 
enters an auction, it will incur a participation cost $e$, obtain its own private information $c$, and submit a bid following a Nash bidding strategy in the second-stage auction game. $e$ is assumed to be identical and common knowledge for all players. In addition, no bidder is allowed to participate in both auctions at the same time. If the set-aside program is effective, the low-end project is exclusively offered to SMEs so that large firms cannot bid. Otherwise, a large firm can be a recipient of the $L$ project.

Despite the simplification, the game has many pure and mixed equilibria depending on the entry process. ${ }^{24}$ Therefore, it is further assumed that entry takes place sequentially, as in McAfee and McMillan (1987a), and that the number of bidders is treated as a continuous variable.

Then, the number of players can be reduced to two, $L B$ and $S B$. Each player $t \in\{L B, S B\}$ decides the number of participants $n_{s, t}$ in the auction for each project $s \in\{H, L\}$ subject to the participation constraint, i.e. $n_{L, L B}=0$ if the set-aside program is effective and $n_{H, S B}=0$. It is also assumed that player $L B$ decides her entry first and, successively, $S B$ makes his participation decision. Once deciding their entry decision $n_{s, t}$, each representative player $t$ incurs participation $\operatorname{costs} e \times n_{s, t}$ for each auction. This setting gives us a unique asymmetric Nash entry equilibrium. The timeline is described in Figure 9.

\subsection{Analysis for the auction stage}

Private values are assumed, i.e., that one bidder's signal does not affect the other's preferences and that bidders are risk-neutral. Each bidder draws his own signal $\sigma$, which is uniformly distributed on $[0,1]$. Let $c_{t}(\sigma)$ denote the cost of a type $t$ bidder, which is increasing and differentiable in $\sigma$ for each $t \in\{S B, L B\}$, with $c_{S B}(0)=c_{L B}(0)=\underline{c}$ and $c_{S B}(1)=c_{L B}(1)=\bar{c}$. Let $U_{t}$ be the expected payoff of a bidder in group $t$ conditional on his signal $\sigma$. In addition, let $\Psi_{t}(b)$ denote the expected payment conditional on his bid value $b$. Then, given the number of bidders $n_{S B}$ and $n_{L B}$, the maximization problem of a type $t$ bidder is given by

$$
U_{t}\left(\sigma \mid n_{S B}, n_{L B}\right) \equiv \max _{b} p_{t}(b)-\Psi_{t}\left(b \mid n_{S B}, n_{L B}\right) c_{t}(\sigma) .
$$

\footnotetext{
${ }^{24}$ Levin and Smith (1994) show that the number of actual bidders will be stochastic if the entry is simultaneous.
} 
If $c_{t}(\cdot)$ is differentiable and $\beta_{t}(\sigma)$ is the bid that maximizes $p_{t}(b)-\Psi_{t}\left(b \mid n_{S B}, n_{L B}\right) c_{t}(\sigma)$, then $\psi_{t}\left(\sigma \mid n_{S B}, n_{L B}\right) \equiv \Psi_{t}\left(\beta_{t}(\sigma) \mid n_{S B}, n_{L B}\right)$ can be defined. The envelope integral formula suggests that the payoff of a type $t$ bidder satisfies

$$
U_{t}\left(\sigma \mid n_{S B}, n_{L B}\right)=U_{t}\left(0 \mid n_{S B}, n_{L B}\right)+\int_{\sigma}^{1} \frac{d}{d \hat{\sigma}} c_{t}(\hat{\sigma}) \psi_{t}\left(\hat{\sigma} \mid n_{S B}, n_{L B}\right) d \hat{\sigma}
$$

Then, let $V_{t}\left(n_{S B}, n_{L B}\right)$ be the ex ante payoff of a bidder from the auction given $n_{L, L B}$ and $n_{L, S B}$. If $U_{t}(0 \mid \cdot, \cdot)$ is normalized as equal to zero, then taking expectation of $U_{t}$ is given by

$$
V_{t}\left(n_{S B}, n_{L B}\right) \equiv E\left[U_{t}\left(n_{S B}, n_{L B}\right)\right]=\int_{0}^{1}(1-\hat{\sigma}) \frac{d}{d \hat{\sigma}} c_{t}(\hat{\sigma}) \psi_{t}\left(\hat{\sigma} \mid n_{S B}, n_{L B}\right) d \hat{\sigma}
$$

For empirical analysis, it is assumed that there exists a function $\tilde{V}_{t}(\cdot)$ such that

$$
\tilde{V}_{t}\left(x_{t}\left(n_{S B}, n_{L B}\right), n\right) \equiv V_{t}\left(n_{S B}, n_{L B}\right)
$$

where $n=n_{S B}+n_{L B}$. The identity indicates that the ex ante expected payoff $V(\cdot)$ can be decomposed into two components, i) the number of competitors represented by $n$, and ii) the firm size represented by $x_{t}$. The value $x_{t}(\cdot)$ in function $\tilde{V}_{t}(\cdot)$ is defined in the same manner as in the previous section. ${ }^{25}$ By linear approximation, $\log \tilde{V}_{t}$ is rewritten as

$$
\log \tilde{V}_{t}\left(x_{t}(\cdot), n\right)=\log \tilde{V}_{t}(0,0)+\log \tilde{V}_{1, t}(0,0) \cdot x_{t}(\cdot)+\log \tilde{V}_{2, t}(0,0) \cdot n
$$

where $\tilde{V}_{1, t}=\frac{\partial \log \tilde{V}_{t}}{\partial x_{t}}$ and $\tilde{V}_{2, t}=\frac{\partial \log \tilde{V}_{t}}{\partial n}$. Let $\log \tilde{V}_{t}(0,0)=\alpha_{0}, \log \tilde{V}_{1, t}(0,0)=\alpha_{1}$, and $\log \tilde{V}_{2, t}(0,0)=$ $\alpha_{2}$. Then, one obtains

$$
\log V_{t}\left(n_{L, S B}, n_{L, L B}\right)=\alpha_{0}+\alpha_{1} \cdot x_{t}\left(n_{L, S B}, n_{L, L B}\right)+\alpha_{2} \cdot n .
$$

\footnotetext{
${ }^{25}$ Let $\bar{X}_{t}$ be the average score of the type $t$ player, which is given and constant for each $t \in\{S B, L B\}$. In addition, let $\bar{X}_{L}$ denote the bidders' average score in the low-end projects, formulated by $\bar{X}_{L}=$ $\left(\bar{X}_{L B} \cdot n_{L, L B}+\bar{X}_{S B} \cdot n_{L, S B}\right) / n_{L}$. According to the definition of $x$, the normalized score of type $t$ firms is given by

$$
x_{t}\left(n_{L, S B}, n_{L, L B}\right)=\frac{\bar{X}_{t}-\bar{X}_{L}}{\bar{X}_{L}} .
$$

The explicit form of $x_{t}(\cdot, \cdot)$ is given in the Appendix. 
The coefficient $\alpha_{1}$ represents the bidder t's elasticity of the $\log$ ex ante expected payoffs with respect to his relative size $x_{t}$.

\subsection{Analysis for an entry equilibrium}

Under the set-aside program, large firms may obtain positive rents since their production capacity is limited, whereas the marginal SME bidder obtains zero ex ante payoff because of participation by an unlimited number of SMEs. Therefore, a unique entry equilibrium must satisfy

$$
\begin{aligned}
& \left\{\begin{array}{l}
V_{S B}\left(n_{L, S B}^{r}, 0\right)=e \\
V_{L B}\left(0, n_{H, L B}^{r}\right) \geq e
\end{array}\right. \\
& \text { subject to } n_{H, L B}^{r} \leq n_{L B} .
\end{aligned}
$$

Without set-asides, low-end projects receive bids from large firms as well although the rent of SMEs is still fully extracted because of the unlimited production capacity of SMEs. Hence, the SMEs' optimal entry decision $n_{L, S B}^{u}$ satisfies

$$
V_{S B}\left(n_{L, S B}^{u}, n_{L, L B}\right)=e
$$

for any $n_{L, L B}$. Solving (10) for $n_{L, S B}$ gives the SMEs' best response $n_{L, S B}^{u}=\Gamma\left(n_{L, L B}\right)$ for any $n_{L, L B}$. Since $V_{S B}$ is decreasing in both $n_{L, S B}^{u}$ and $n_{L, L B}^{u}, \Gamma^{\prime}\left(n_{L, L B}^{u}\right)<0$ is obtained. In addition, the number of large firms in the market is given and finite, and that each bidder with a unit production capacity can bid only once. Therefore, the number of large bidders in high-end projects $n_{H, S B}$ is a decreasing function of $n_{L, L B}$, namely:

$$
n_{H, S B}=\Lambda\left(n_{L, L B}\right)
$$


In equilibrium, the ex ante payoff of each large bidder must be the same between the two projects. Hence, the following is obtained:

$$
\begin{gathered}
V_{L B}\left(\Gamma\left(n_{L, L B}^{u}\right), n_{L, L B}^{u}\right)=V_{L B}\left(0, \Lambda\left(n_{L, L B}^{u}\right)\right) \\
\text { subject to } 0 \leq n_{L, L B}^{u} \leq n_{L B} .
\end{gathered}
$$

It is noteworthy that the left-hand side represents the ex ante payoff from low-end projects. This equation gives a unique solution of $n_{L, L B}^{u}$.

\subsection{An empirical model for auctions with entry}

According to MLIT (2007), civil engineering projects with their engineer's estimated costs being less than $¥ 300$ million are set aside for SMEs. ${ }^{26}$ Consequently, with this model, we considers that a project is high-end if the engineer’s estimated cost is no less than $¥ 300$ million and low-end if the estimated cost is less than $¥ 300$ million. The proportion of low-end projects in volume account for approximately 61 percent of the total budget for civil engineering contracts during the period.

The bidders are then divided into either large firms or SMEs. In fact, the distinction between SMEs and large firms in the data is somewhat ambiguous. The set-aside program allows large firms to participate in relatively small projects unless a sufficient competition among SMEs is expected. Consequently, quite a few large firms submit their bids in low-end projects. In addition, some SMEs that met a quality standard were able to participate in some high-end projects. Hence, one dependable way to distinguish these two groups of firms would be to assume that those that bid on high-end projects are large firms and those that bid on low-end projects are SMEs. Since the average scores in high- and low-end projects are 1,370.9 and 983.3, respectively, $\bar{X}_{S B}=983.3$ and $\bar{X}_{L B}=1,370.9$ were set. Table 7 is a summary of the statistics of the bidders' scores in both high- and low-end projects.

Let $\bar{n}_{s, t}$ be the number of average bidders with type $t \in\{S B, L B\}$ in category $s \in\{H, L\}$

\footnotetext{
${ }^{26}$ More precisely, $¥ 300$ million is the threshold value with which the government determines whether a project is auctioned for contractors that are grade $\mathrm{B}$ or above or $\mathrm{C}$ or below. Although the contractors with $\mathrm{C}$ or below may not satisfy the exact criteria of "SMEs" in Japan, the empirical analysis used here considers them as SMEs for simplicity.
} 
projects. Denoting by $\bar{n}_{L, S B}^{r}$ and $\bar{n}_{L, S B}^{r}$ the equilibrium participation under the set-aside program, $\bar{n}_{L, S B}^{r}=7.87$ and $\bar{n}_{H, L B}^{r}=8.20$ are obtained from the data. ${ }^{27}$ Then, a counterfactual simulation is conducted to predict $\bar{n}_{s, t}^{u}$.

First, the bidders' ex ante payoffs are identified. Let $b_{1, k}$ be the lowest bid in auction $k$. In addition, with a little abuse of notation, let $c_{1, k}$ be the estimated cost of the lowest bidder. ${ }^{28}$ Since the bid margin is a consistent estimator for the conditional payoff $\pi_{1, k}$, the estimator of the conditional payoff is defined as $\hat{\pi}_{1, k}=b_{1, k}-c_{1, k}$.

Now, let $V_{1, k}$ denote the ex ante payoff of the lowest bidder in the $k$ th auction. In the risk-neutral environment, it equals the bid margin times the probability of winning, namely

$$
V_{1, k}=y_{1, k} \cdot \pi_{1, k}
$$

where $y_{1, k}$ implies the winning probability of the lowest bidder in the $k$ th auction. To estimate $y_{1, k}$, a simple linear probability regression model is used: let $y_{i, k}$ be the index of the $i$ th lowest bidder's awarding in the $k$ th auction where $y_{i, k}=1$ if the bidder wins and $y_{i, k}=0$ otherwise. Then, the probability is given by

$$
y_{i, k}=\delta_{1} \frac{1}{n_{k}}+\delta_{2} x_{i, k}+\delta_{3} \mathbf{z}_{k}+\nu_{k}
$$

where $\mathbf{z}_{k}=\left(\mathrm{DATE}_{k}, \mathrm{EST}_{k}, \log \mathrm{EST}_{k}, \mathrm{DUMMY}_{k}\right)$.

Table 8 shows the regression results of Equation (14). Fixed effects control the unobserved heterogeneity in project locations. Due to the fact that the mean difference in scores for SMEs is 39 percent lower than that for large firms, ${ }^{29}$ it can be concluded that the mean difference in frequency of winning for SMEs is approximately 5.2 percent lower than that for large firms (t-value : 7.59 with FE).

Furthermore, denoting by $\hat{\delta}$ the least square estimates of (14), the estimated winning prob-

\footnotetext{
${ }^{27}$ They are estimated by $\bar{n}_{s, t}=\frac{\sum_{k=1}^{m} \mathbf{1}\left\{s_{k}=s\right\} \cdot n_{k, t}}{\sum_{k=1}^{m} \mathbf{1}\left\{s_{k}=s\right\}}$ for each $s \in\{H, L\}$, where $n_{k, t}$ is the number of type $t$ bidders in the $k$ th sample auction with $t \in\{L B, S B\}$.

${ }^{28}$ Since our model assumes the asymmetric first-price sealed-bid procurement auctions, it is possible that the lowest bidder does not have the lowest signal.

$29 \frac{\bar{X}_{B B}-\bar{X}_{S B}}{\bar{X}_{B B}}=0.39$.
} 
ability EST PRWIN is obtained as

$$
\operatorname{EST} \operatorname{PRWIN}_{1, k}=\hat{\delta}_{1} \frac{1}{n_{k}}+\hat{\delta}_{2} x_{1, k}+\delta_{3} \mathbf{z}_{k}
$$

Then, using (13), a consistent estimator for $V_{1, k}$ is obtained by $\hat{V}_{1, k}=\operatorname{EST}_{\text {PRWIN }} \operatorname{RH}_{1, k} \cdot \hat{\pi}_{1, k}$. Now, plugging $\hat{V}_{1, k}$ into (8) and assuming that $\epsilon_{k}$ is an i.i.d., mean zero random variable, the following is obtained:

$$
\log \hat{V}_{1, k}=\alpha_{0}+\alpha_{1} x_{1, k}+\alpha_{2} n_{k}+\epsilon_{k}
$$

Let $\hat{\alpha}_{1}, \ldots, \hat{\alpha}_{3}$ be the least square estimates of $\alpha$. Take the expectation on both sides, and one obtains

$$
E\left(\log \hat{V}_{1}\right)=\hat{\alpha}_{0}+\hat{\alpha}_{1} E\left(x_{1}\right)+\hat{\alpha}_{2} E(n) .
$$

The regression results are shown in Table 9. To obtain the model for the simulation, the expectations are replaced by $\bar{V}=\frac{1}{m} \sum_{k} \log V_{1, k}, \bar{x}=\frac{1}{m} \sum_{k} x_{1, k}$, and $\bar{n}=\frac{1}{m} \sum_{k} n_{k}$. Furthermore, it is assumed that this equation holds for each group of bidders and each type of project. Let $\bar{V}_{s, t}$ and $\bar{x}_{s, t}$ represent the average ex ante log payoff and the score of type $t$ winning bidders in category $s$ projects. Then, it is assumed that

$$
\bar{V}_{s, t}=\hat{\alpha}_{0}+\hat{\alpha}_{1} \bar{x}_{s, t}+\hat{\alpha}_{2} \bar{n}_{s}
$$

holds for any $s$ and $t$, where $\bar{n}_{s}=\bar{n}_{s, S B}+\bar{n}_{s, L B}$.

Equation (15) constitutes the counterfactual simulation, where $\hat{\alpha_{2}}$ captures the marginal effect of bidder's size on the profitability. In addition, it is used to identify the participation cost $e$. Plugging it into (9) gives the estimator of the entry cost $e$ as:

$$
\log \hat{e}=\hat{\alpha}_{0}+\hat{\alpha}_{2} \bar{n}_{L, S B}^{r}
$$


Finally, the individual rationality condition for large firms is checked. From (15) and (9),

$$
\hat{\alpha}_{0}+\hat{\alpha}_{2} \bar{n}_{H, L B}^{r} \geq \log e
$$

must hold in equilibrium. In our model, the value of the left-hand side is 0.96 percent, which is greater than the right-hand side of 0.95 percent.

\section{Simulation}

\subsection{The model}

First, the follower's problem in the entry game is considered. Plug (7) into (15), and the ex ante payoff function $V(\cdot)$ of SMEs is obtained such that

$$
\bar{V}_{S B}\left(\bar{n}_{L, S B}^{u}, \bar{n}_{L, L B}^{u}\right)=\hat{\alpha}_{1}+\hat{\alpha}_{2} \cdot \bar{x}_{S B}\left(\bar{n}_{L, S B}^{u}, \bar{n}_{L, L B}^{u}\right)+\hat{\alpha}_{3} \cdot\left(\bar{n}_{L, S B}^{u}+\bar{n}_{L, L B}^{u}\right)
$$

$\bar{V}_{S B}\left(\bar{n}_{L, S B}^{u}, \bar{n}_{L, L B}^{u}\right)=e$ holds in equilibrium. Solving for $n_{S B}$ on this equation gives the explicit form of the best response function $\Gamma(\cdot)$. The complete derivation is provided in the Appendix.

Next, the ex ante payoff of large firms in the low-end project is given by

$$
\bar{V}_{L B}\left(\bar{n}_{L, S B}^{u}\right)=\hat{\alpha}_{1}+\hat{\alpha}_{2} \cdot \bar{x}_{L B}\left(\Gamma\left(\bar{n}_{L, S B}^{u}\right), \bar{n}_{L, S B}^{u}\right)+\hat{\alpha}_{3} \cdot\left(\Gamma\left(\bar{n}_{L, S B}^{u}\right)+\bar{n}_{L, S B}^{u}\right)
$$

which is expressed as a function of $\bar{n}_{L, S B}^{u}$. Therefore, Equation (13) in the simulation study becomes

$$
\hat{\alpha}_{2} \cdot \bar{x}_{L B}\left(\Gamma\left(\bar{n}_{L, L B}^{u}\right), \bar{n}_{L, L B}^{u}\right)+\hat{\alpha}_{3} \cdot\left(\Gamma\left(\bar{n}_{L, L B}^{u}\right)+\bar{n}_{L, L B}^{u}\right)=\lambda \cdot \hat{\alpha}_{3} \cdot \Lambda\left(\bar{n}_{L, L B}^{u}\right) .
$$

The left-hand side describes the large businesses' ex ante expected payoff from low-end projects, whereas the right-hand side equals to the ex ante expected payoff from high-end projects. Since low-end projects are greater in value terms than high-end projects, a weight variable $\lambda$ is introduced so that (17) describes an equilibrium in which the gain of a large firm from entering the low-end market is identical to that from entering the high-end market. For simplicity in 
simulation calculation, $\Gamma(\cdot)$ and $\Lambda(\cdot)$ are linearized in Equation (17). The details are described in the Appendix.

Finally, the comparative statics of the winning bid are described with respect to the participation restriction. Let $b_{1, k}$ be the lowest bid in auction $k$. For any $k=1, \ldots m$, the distribution of $b_{1, k}$ is written as $^{30}$

$$
G_{b_{1, k}}\left(b_{1, k} \mid x_{k}, n_{k}, z_{k}\right)=\prod_{\tau=1}^{n_{k}}\left\{1-G_{b_{\tau, k}}\left(b_{1, k} \mid x_{\tau, k}, n_{k}, z_{k}\right)\right\}
$$

In other words, $b_{1, k}$ is a random variable given the numbers of bidders, the normalized score of each bidder, and exogenous variables, such as the auction specific effect.

To know the effect of the winning bidder's size on the winning bid, a linear regression model was established for the lowest bids. Assuming that $\epsilon_{b_{1}}$ follows an i.i.d. distribution, the model is given as

$$
b_{1, k}=\beta_{0}+\beta \cdot x_{1, k}+\beta_{2} \cdot n_{k}+\beta_{3} \cdot \mathbf{z}_{k}+\epsilon_{b_{1}}
$$

where $n_{k}$ and $z$ control for the number of bidders and other auction-specific effects, respectively. Then, $\hat{\beta}_{1}$ measures the difference of the winning bid between large firms and SMEs.

Table 10 shows the result of the regression of the lowest bids on $x$. Again, the lowest bid in the $k$ th auction sample is denote by $b_{1, k}$. Fixed effects control the area specific effects. This regression indicates that the winning bid decreases as the number of bidders increases or the bidder's score $x$ is higher.

Finally, the mean winning bids are derived in the low-end projects by using the above regression. Under the set-aside program, only SMEs are the bidders in the low-end projects. Hence, the mean lowest bids is given by

$$
\bar{b}_{1, L}^{r}=\beta_{0}+\beta_{2} \cdot n_{L, S B}^{r}
$$

In case of unrestricted participation, both large firms and SMEs will win the low-end project

\footnotetext{
${ }^{30}$ Recall that the bidding function depends upon $b_{i, k}, x_{i, k}, n_{k}$ and $z_{k}$, and $c_{i, k}$ is a random variable subject to $F_{c_{i}}\left(c_{i, k} \mid \mathbf{z}_{k}\right)$.
} 
with probabilities equal to $\hat{y}_{1, L B} \cdot \bar{n}_{L, L B}$ and $\hat{y}_{1, S B} \cdot \bar{n}_{L, S B}$. Define $\bar{n}_{L}^{u} \equiv \bar{n}_{L, L B}+\bar{n}_{L, S B}$ as the mean number of bidders in low-end projects. Then, it is assumed that the mean winning bids of large firms and SMEs can be described by

$$
\begin{array}{r}
\bar{b}_{1, L B}^{u}=\hat{\beta}_{0}+\hat{\beta}_{1} \cdot \bar{x}_{L B}(\cdot)+\hat{\beta}_{2} \cdot \bar{n}_{L}^{u}, \\
\text { and } \bar{b}_{1, S B}^{u}=\hat{\beta}_{0}+\hat{\beta}_{1} \cdot \bar{x}_{S B}(\cdot)+\hat{\beta}_{2} \cdot \bar{n}_{L}^{u}
\end{array}
$$

Then, the mean winning bids in the low-end projects are given as

$$
\bar{b}_{1, L}^{u}=\bar{b}_{1, L B}^{u} \cdot \hat{y}_{1, L B} \cdot \bar{n}_{L, L B}+\bar{b}_{1, S B}^{u} \cdot \hat{y}_{1, S B} \cdot \bar{n}_{L, S B}
$$

The marginal effect by restricting participation is given by $\bar{b}_{1, L}^{r}-\bar{b}_{1, L}^{u}$.

\subsection{Results}

The empirical results suggest that the set-aside program likely decreases procurement costs. A counterfactual simulation predicts what the bidder's entry decision and bidding behavior would be were the program to be eliminated. The program yields the competing effects in terms of government procurement costs, the cost reduction in set-aside projects and the cost increase in the remaining projects.

The simulation study suggests that, were the program to be eliminated, 3.54 large firms on average would switch their entry from high-end to low-end projects so that their ex ante payoff from these two projects must be identical in equilibrium. Since there is a difference in volume for each category of projects, represented by $\lambda=0.65$, the mean number of large firms in low-end projects would be 2.28 , which is obtained by 3.54 times $\lambda$.

The serious problem by removing the participation restriction is that the participants would decrease in both high- and low-end projects. In high-end projects, the number of large firms would drop from 8.20 to 4.66 , which would raise the procurement costs of those projects by 1.4 percent. At the same time, the large firms' participation in the low-end projects would depress SME entry into the low-end projects. The mean number of SME participants would decline from 
7.87 to $4.86 .^{31}$ The number of both large-firm and SME participants in low-end projects would drop from 7.87 to 7.14 on average since, according to the static entry model, the participation of one more large firm in the low-end projects would eliminate 1.32 SME participants on average. ${ }^{32}$ The procurement costs of low-end projects would fall by 47 percent, despite the presence of fewer participants, because of the entry of cost-efficient large firms. The average score of bidders would be increased from 983.3 to $1,107.2$.

Surprisingly, the resulting lack of competition would drive up government procurement costs. There are two competing effects that set-asides have on government procurement costs, increasing competition versus the participation of cost-inefficient SMEs. Taking also into account the fact that the government spent approximately 60 percent of the procurement budget on low-end projects, the effect of increasing competition would overcompensate the effect of production inefficiency cost. The simulation study suggests that set-asides would decrease government procurement costs by 0.28 percent.

It is interesting to observe how the ex ante expected profits of large firms are changed by set-asides. Without set-asides, large firms obtain a positive expected gain (1.82 percent of the engineer's estimated cost for each auction), and the net positive gain from entry is almost 1 percent of the project estimated cost. Set-asides completely squeeze the positive net gain from the large firms so that the expected gain of large firms with set-asides is almost zero (0.01 percent). Obviously, this rent extraction from large firms contributes to lowering government procurement costs more than to offset the resulting production cost inefficiency.

\section{Discussion}

Most small business programs declare that the importance of giving more contract opportunities for disadvantaged businesses lies in the encouragement of their long-run growth. The long-run benefit on an economy has been assumed to outweigh the short-run cost of supporting small businesses. In fact, even in the short run, the program can benefit the procurement buyer, as our analysis has illustrated. Upon designing a public procurement policy, the non-trivial short-run

\footnotetext{
${ }^{31}$ This outcome implicitly assumes that each group of bidders follows a Nash equilibrium bidding strategy. Should the large firms intentionally make a low-ball bid to deter entry by SMEs, the decrease of SMEs would be much more significant.

${ }^{32}$ The coefficient is given by $\gamma=1.32$.
} 
gain should be more carefully considered.

In addition, set-asides are robust against collusion in procurement auctions. Our simulation results indicate that both high-end and low-end auctions receive more participants when setasides are in use. Obviously, more participants in auctions implies fewer chances for bidders to be cooperative. Procurement buyers may, therefore, have further short-run benefit from set-asides.

The assumption that the firm has unit production capacity can be relaxed so that multiple units of production and, hence, participating in more than two auctions at the same time are possible without changing the obtained results in this analysis. However, the model does rely on

the production capacity, especially, the capacity constraint of the cost-efficient businesses. It is easy to imagine that procurement costs would always be lower by inviting only the cost-efficient firms if their production always exhibits constant returns to scale, although the situation is unrealistic for many procurement buyers.

\section{Conclusion}

Set-asides are widely used in real-world public procurement. The encouragement of SMEs has evoked a controversy on the extent of the extra cost society is paying. However, there is no previous systematic analysis to measure the impact on procurement costs.

In this paper, we provide the first systematic analysis of the effect of small business set-asides on government procurement costs, bidding behaviors, and bidder participation in competitive bidding processes. The simulation study suggests that the program dramatically increases SME participation but is almost neutral with respect to the procurement costs. The production inefficiency caused by set-asides is overcompensated by the increased entry and resulting enhancement of competition by large firms. The set-aside program was observed to increase SME participation in the procurement auctions by approximately 40 percent.

The empirical results show that the set-aside program has been successful. It improves equity between advantaged and disadvantaged firms and reduces government procurement costs. The results also suggest that the government cost of set-aside auctions is exaggerated if only the excess amount on contracts allocated to SMEs is considered. The theoretical literature suggests that, despite the efficiency loss, the encouragement of less advantaged bidders in the auction can 
reduce procurement costs. For instance, Bulow and Roberts (1989) and McAfee and McMillan (1989) insist that bidding credits (or bid discounts in procurement auctions) for disadvantaged bidders increase the auctioneer's welfare, yielding more competitive pressure on advantaged bidders. Similarly, the subsidized SMEs drive non-subsidized bidders to give up more of the gain on the contracts they award.

The conclusion also provides an economic rationale on why several countries such as the United States and Japan opt out of SMEs from the Government Procurement Agreement (GPA) of the World Trade Organization (WTO). Although Article 4 in the GPA prohibits the member countries to give unfavored treatment to any company, the set-aside programs are exempted in the GPA Appendix. EU countries have also been renegotiating with the WTO to obtain the exclusion of their SMEs. An important question, however, is whether those practices are robust to corruption or favoritism. Further theoretical and empirical consideration is needed.

A limitation of this study is that it does not consider the long-term effect of set-asides. In the long run, there are positive and negative effects of set-asides on procurement costs. If SMEs could win more auctions, they would have more chances to develop their production skills through learning by doing. On the other hand, subsidization of SMEs may discourage them to develop their businesses to a stage in which they could not be favored in the preference program. Given the sheer volume of public sector procurement, it is clear that more serious research and evaluation are needed to investigate the long-run effect of the set-aside program.

\section{Appendix}

\section{An alternative proof for Zhang and Guler (2005)}

The inverse bidding function in asymmetric auction, $\theta_{i}\left(b_{i}\right)$, satisfies the following first-order condition.

$$
\theta_{i}\left(b_{i}\right)=b_{i}-\frac{1}{\sum_{-i} \frac{f_{-i}\left(\theta_{-i}\left(b_{i}\right)\right) \theta_{-i}^{\prime}\left(b_{i}\right)}{1-F_{-i}\left(\theta_{-i}\left(b_{i}\right)\right)}} \quad \forall i=1, \ldots, n
$$


If the inverse bidding functions are monotone, applying a change-of-variables argument yields

$$
\begin{aligned}
G_{-i}(z) & =F_{-i}\left(\theta_{-i}(z)\right) \\
g_{-i}(z) & =f_{-i}\left(\theta_{-i}(z)\right) \theta_{-i}^{\prime}(z) \quad \forall \mathbf{z} \in[\underline{b}, \bar{b}] .
\end{aligned}
$$

Therefore, they can be simplified as

$$
\theta_{i}\left(b_{i}\right)=b_{i}-\frac{1}{\sum_{-i} \frac{g_{-i}\left(b_{i}\right)}{1-G_{-i}\left(b_{i}\right)}} \quad \forall i=1, \ldots, n
$$

Without loss of generality, set $\mathrm{i}=1$. Then, the inverse bidding function for bidder 1 is rewritten as

$$
\theta_{1}\left(b_{1}\right)=b_{1}-\frac{1}{\left\{\frac{g_{2}\left(b_{1}\right)}{1-G_{2}\left(b_{1}\right)}+\frac{g_{3}\left(b_{1}\right)}{1-G_{3}\left(b_{1}\right)}+, \ldots,+\frac{g_{n}\left(b_{1}\right)}{1-G_{n}\left(b_{1}\right)}\right\}} .
$$

Reducing to a common denominator, the summation in the curly bracket is rewritten as

$$
\frac{\left[\prod_{k \neq\{1,2\}}\left\{1-G_{k}\left(b_{1}\right)\right\}\right] g_{2}\left(b_{1}\right)+, \ldots,+\left[\prod_{k \neq\{1, n\}}\left\{1-G_{k}\left(b_{1}\right)\right\}\right] g_{n}\left(b_{1}\right)}{\prod_{k \neq 1}\left\{1-G_{k}\left(b_{1}\right)\right\}} .
$$

Let $1-G_{1}^{*}\left(b_{1}\right)=\prod_{k \neq 1}\left\{1-G_{k}\left(b_{1}\right)\right\}$. Assume $\exists g_{1}^{*}\left(b_{1}\right)=\frac{\partial G_{1}^{*}\left(b_{1}\right)}{\partial b_{1}}$. Then

$$
g_{1}^{*}\left(b_{1}\right)=\left[\prod_{k \neq\{1,2\}}\left\{1-G_{k}\left(b_{1}\right)\right\}\right] g_{2}\left(b_{1}\right)+, \ldots,+\left[\prod_{k \neq\{1, n\}}\left\{1-G_{k}\left(b_{1}\right)\right\}\right] g_{n}\left(b_{1}\right) .
$$

So $(\mathrm{A}-1)$ can be rewritten as

$$
c_{1}=b_{1}-\frac{1-G_{1}^{*}\left(b_{1}\right)}{g_{1}^{*}\left(b_{1}\right)} .
$$

To interpret $G_{1}^{*}(\cdot)$, let $B_{1}=\min _{k \neq 1} b_{k}$. Then, it is shown to be the cumulative distribution of bids as follows:

$$
\begin{array}{r}
1-G_{1}^{*}(x) \equiv \prod_{k \neq 1}\left\{1-G_{k}(x)\right\}=\operatorname{Pr}\left(x \leq B_{1}\right), \\
g_{1}^{*}(x) \equiv \frac{\partial G_{1}^{*}(x)}{\partial b_{1}}=\operatorname{Pr}\left(x=B_{1}\right)
\end{array}
$$

If there are $m$ sample auctions with identical set of bidders, and if we let $B_{1, j}=\min _{k \neq 1} b_{1, j}$ 
for all $j$, then we obtain the non-parametric estimators for both $G$ and $g$ as follows:

$$
\begin{aligned}
1-\hat{G}_{1}^{*}(B) & =\frac{1}{m} \sum_{j=1}^{m} \mathbf{1}\left(B \leq B_{1, j}\right), \\
\hat{g}_{1}^{*}(B) & =\frac{1}{m h_{g}} \sum_{j=1}^{m} K_{g}\left(\frac{B-B_{1, j}}{h_{g}}\right) .
\end{aligned}
$$

\section{Linearization of $\Lambda(\cdot)$}

Let $s_{k} \in\{H, L\}$ be the category of project $j$. The substitution effect of entry by large firms between low- and high-end projects is then considered. Data exhibit that the amount of highend contracts is $¥ 851.80$ billion and that of low-end contracts is $¥ 1,319.16$ billion during the observation period, each of which is computed by the sum of engineer's estimated costs for each project. Due to the fact that the production capacity is likely to be fulfilled only for large firms (see Section 4), it is assumed that the capacity constraint is binding in large firms. Because of the difference in value for each category of projects, the withdrawal of a large firm from high-end projects to bid for low-end projects does not necessarily imply the increase by one more large bidder in low-end projects. This is captured by Equation (11).

Originally (with the set-aside program), the equilibrium numbers of participants are $n_{H, S B}=$ $n_{H, S B}^{r}$ and $\left.n_{L, L B}=0\right)$ so that (11) is given by

$$
n_{H, S B}^{r}=\Lambda(0),
$$

Equation (11) also implies that, were the set-aside program to be removed, then for some $n_{H, S B}^{u}$ and $n_{L, L B}^{u}$

$$
n_{H, S B}^{u}=\Lambda\left(n_{L, L B}^{u}\right)
$$

The linear approximation of (A-3) evaluated at $n_{H, S B}=n_{H, S B}^{r}$ and $n_{L, L B}=0$ is thus given by

$$
n_{H, S B}^{u}=\Lambda(0)+\Lambda^{\prime}(0) \Delta \bar{n}_{L, L B}^{u}
$$


By (A-2) and $\Delta \bar{n}_{L, L B}^{u}=\bar{n}_{L, L B}^{u}$, one obtains

$$
\bar{n}_{H, L B}^{u}=\bar{n}_{H, L B}^{r}-\lambda \bar{n}_{L, L B}^{u},
$$

where $\lambda=-\Lambda^{\prime}(0)$. In the counterfactual simulation, it is assumed that $\lambda=\frac{851.80}{1319.16}(=0.65)$.

\section{Linearization of $\Gamma(\cdot)$}

The linear approximation for $\bar{n}_{L, S B}^{u}=\Gamma\left(\bar{n}_{L, L B}^{u}\right)$ at $\bar{n}_{L, L B}^{u}=0$ is given by,

$$
\bar{n}_{L, S B}^{u}=\Gamma(0)-\Gamma^{\prime}(0) \Delta \bar{n}_{L, L B}^{u} .
$$

Since $\Gamma(0)=\bar{n}_{L, S B}^{r}$ and $\Delta \bar{n}_{L, L B}^{u}=\bar{n}_{L, L B}^{u}$, one obtains

$$
\bar{n}_{L, S B}^{u}=\bar{n}_{L, S B}^{r}-\gamma \bar{n}_{L, L B}^{u} .
$$

To get the explicit form of $\Gamma(0)$ take total derivative of (16) with respect to $\bar{n}_{L, S B}$ and $\bar{n}_{L, L B}$, and the following is obtained

$$
0=\hat{\alpha}_{2} \cdot \frac{\partial \bar{x}_{L, S B}(\cdot)}{\partial \bar{n}_{L, S B}} \Delta \bar{n}_{L, S B}+\hat{\alpha}_{2} \cdot \frac{\partial \bar{x}_{L, S B}(\cdot)}{\partial \bar{n}_{L, L B}} \Delta \bar{n}_{L, L B}+\hat{\alpha}_{3} \cdot\left(\Delta \bar{n}_{L, S B}+\Delta \bar{n}_{L, L B}\right),
$$

where $\bar{n}_{L}=\bar{n}_{L, S B}+\bar{n}_{L, L B}$.

By the chain rule, $\frac{\partial \bar{x}_{L, S B}(\cdot)}{\partial \bar{n}_{t, L}}=\frac{\partial \bar{x}_{L, S B}(\cdot)}{\partial \bar{X}_{L}} \cdot \frac{\partial \bar{X}_{L}}{\partial \bar{n}_{t, L}}$ holds for each $t \in\{S B, L B\}$. Since $\frac{\partial \bar{x}_{L, S B}(\cdot)}{\partial \bar{X}_{L}}=$ $-\frac{\bar{X}_{S B}}{\left(\bar{X}_{L}\right)^{2}}, \frac{\partial \bar{X}_{L}}{\partial \bar{n}_{L, S B}}=0$ and $\frac{\partial \bar{X}_{L}}{\partial \bar{n}_{L, L B}}=\frac{\left(\bar{X}_{L B}-\bar{X}_{S B}\right) \bar{n}_{L, S B}^{r}}{\left(\bar{n}_{L}\right)^{2}}$ with $\bar{X}_{L}=\bar{X}_{S B}$ and $\bar{n}_{L}=\bar{n}_{L, S B}^{r}$, one obtains

$$
\begin{aligned}
\frac{\partial \bar{x}_{L, S B}(\cdot)}{\partial \bar{n}_{L, L B}} & =-\frac{\bar{X}_{L B}-\bar{X}_{S B}}{\bar{X}_{S B} \cdot \bar{n}_{L, S B}^{r}} \\
\frac{\partial \bar{x}_{L, S B}(\cdot)}{\partial \bar{n}_{L, S B}} & =0 .
\end{aligned}
$$

Plug them into Equation (A-7), and the following is obtained

$$
-\Delta \bar{n}_{L, S B}=\gamma \Delta \bar{n}_{L, L B},
$$


where $\gamma=\frac{\hat{\alpha}_{2}}{\hat{\alpha}_{3}} \frac{\bar{X}_{L B}-\bar{X}_{S B}}{\bar{X}_{S B} \cdot \bar{n}_{L, S B}^{r}}+1=1.32$

\section{References}

Athey, Susan and Jonathan Levin, "Set-Asides and Subsidies in Auctions"," Working Paper, 2006.

Ayres, Ian and Peter Cramton, "Deficit Reduction Through Diversity: How Affirmative Action at the FCC Increased Auction Competition," Technical Report 1996.

Bajari, Patrick and Steven Tadelis, "Incentives versus Transaction Costs: A Theory of Procurement Contracts," RAND Journal of Economics, Autumn 2001, 32 (3), 387-407.

Bannock, Graham, The Economics of Small Firms: Return from the Wilderness, Oxford: Basil Blackwell, 1981.

Bulow, Jeremy and John Roberts, "The Simple Economics of Optimal Auctions," Journal of Political Economy, October 1989, 97 (5), 1060-90.

Campo, Sandra, Isabelle Perrigne, and Quang Vuong, "Asymmetry in first-price auctions with affiliated private values," Journal of Applied Econometrics, 2003, 18 (2), 179-207.

Corns, Allan and Andrew Schotter, "Can Affirmative Action Be Cost Effective? An Experimental Examination of Price-Preference Auctions," American Economic Review, March 1999, 89 (1), 291-305.

Denes, Thomas A., "Do Small Business Set-Asides Increase the Cost of Government Contracting?," Public Administration Review, 1997, 57 (5), 441-444.

Guerre, Emmanuel, Isabelle Perrigne, and Quang Vuong, "Optimal Nonparametric Estimation of First-Price Auctions," Econometrica, 2000, 68 (3), 525-574.

Laffont, Jean-Jacques and Jean Tirole, A theory of incentives in procurement and regulation, Cambridge, MA: The MIT Press, 1994.

Levin, Dan and James L Smith, "Equilibrium in Auctions with Entry," American Economic Review, June 1994, 84 (3), 585-99. 
Marion, Justin, "Are bid preferences benign? The effect of small business subsidies in highway procurement auctions," Journal of Public Economics, August 2007, 91 (7-8), 1591-1624.

McAfee, R. Preston and John McMillan, "Auctions and Bidding," Journal of Economic Literature, June 1987, 25 (2), 699-738.

_ and _, "Auctions with entry," Economics Letters, 1987, 23 (4), 343-347.

_ and _ , "Government procurement and international trade," Journal of International Economics, May 1989, 26 (3-4), 291-308.

Milgrom, Paul, Putting Auction Theory to Work, Campridge University Press, 2004.

MLIT, Ministry of Land, Infrastructure, Transportation and Tourism, Construction Contracts: Annual Report: Tyokkatsu Koji Keiyaku Kankei Shiryou 2007. available at http://www.mlit.go.jp/chotatsu/contractsystem/keiyaku/.

Zhang, Bin and Kemal Guler, "Nonparametric estimation of asymmetric first price auctions: A simplified approach," Economics Letters, September 2005, 88 (3), 318-322.

Zheng, Charles Z., "High Bids and Broke Winners," Journal of Economic Theory, September 2001, 100 (1), 129-171. 


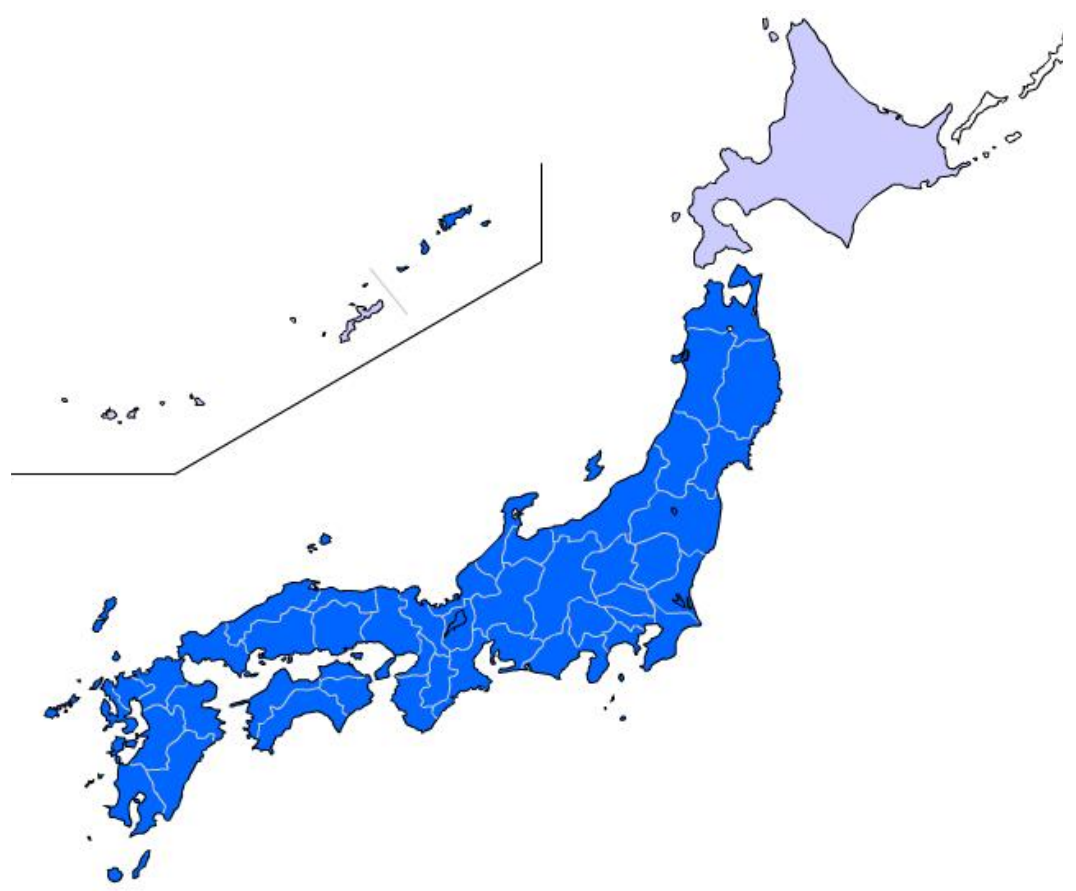

Figure 1: Data area

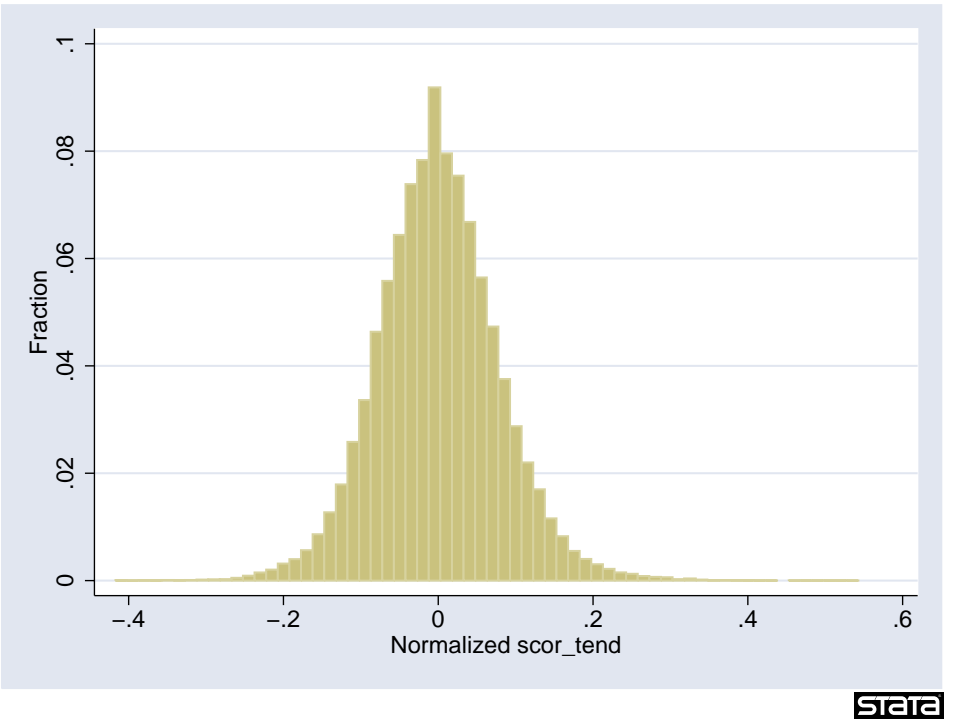

Figure 2: Normalized score of actual bidders 


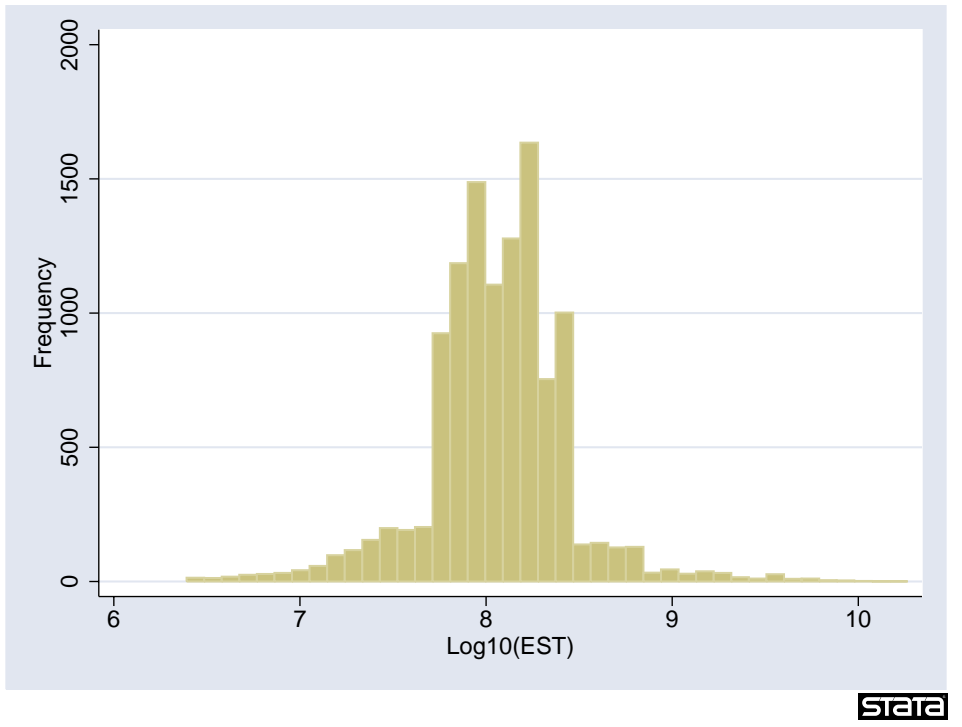

Figure 3: Project size ( $\log _{10}$ of the engineer's estimate)

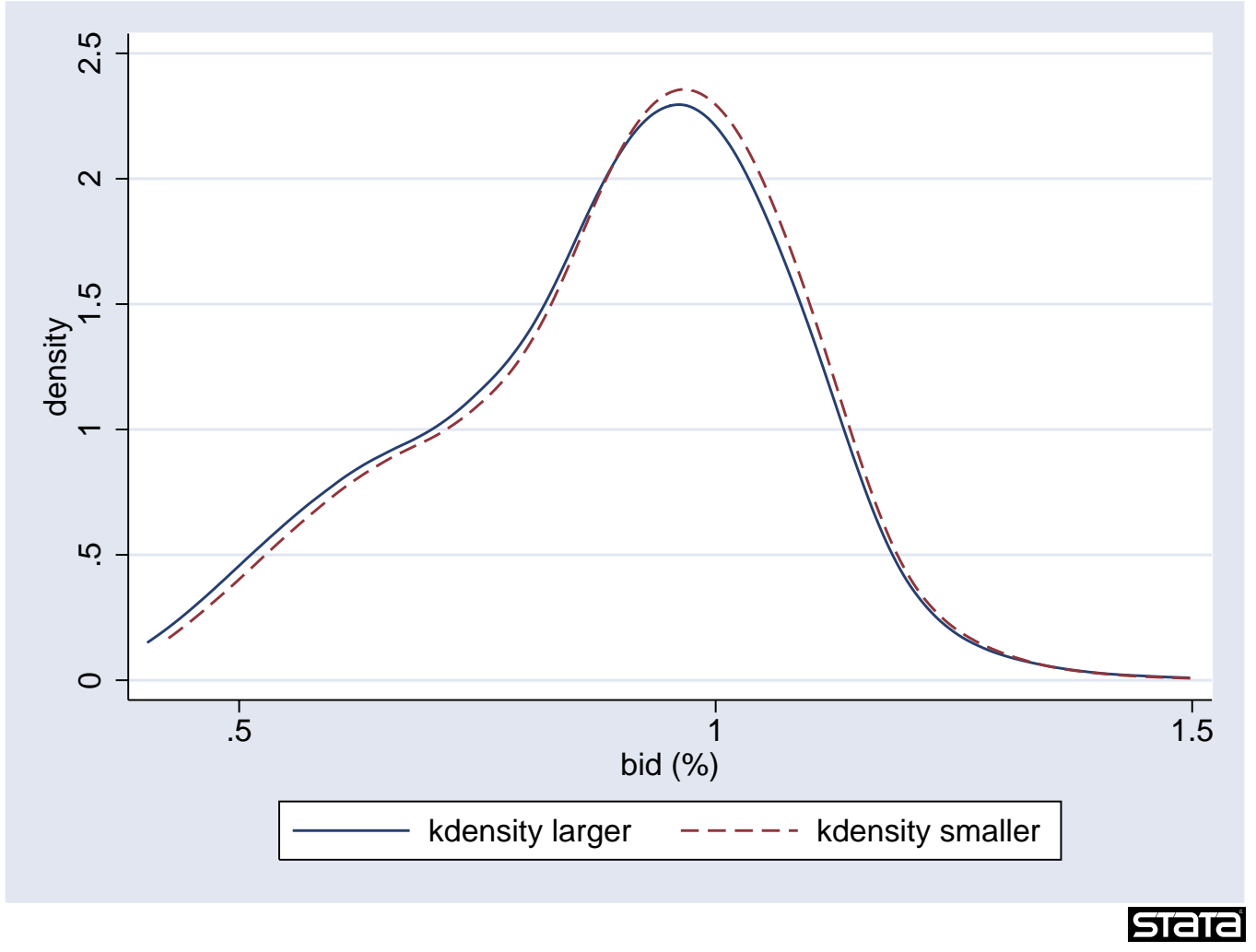

Figure 4: Densities (Percentage bids) 


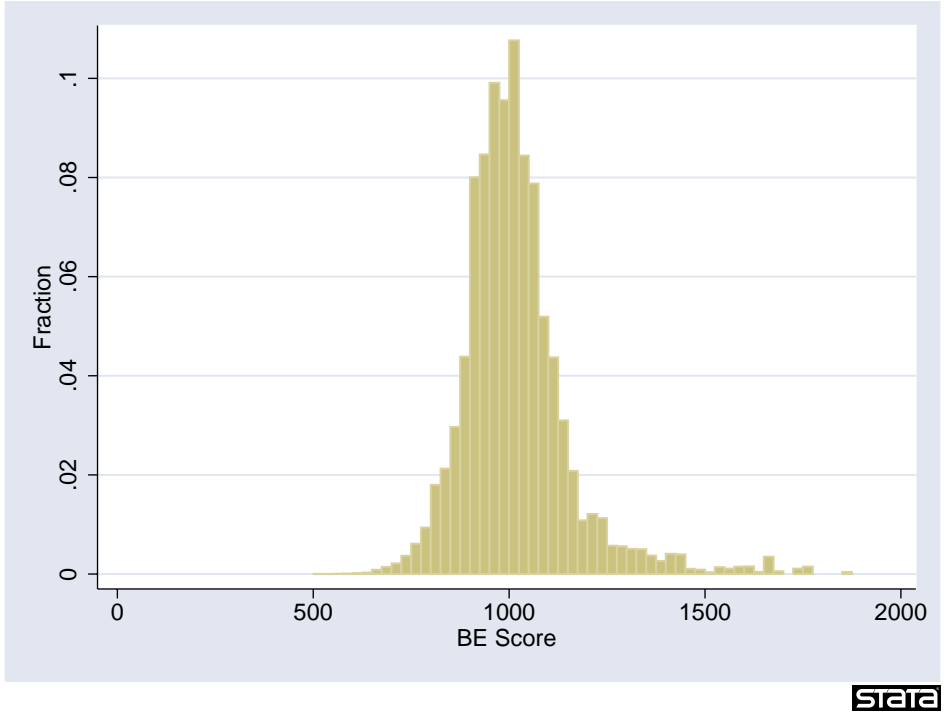

Figure 5: BE score of actual bidders

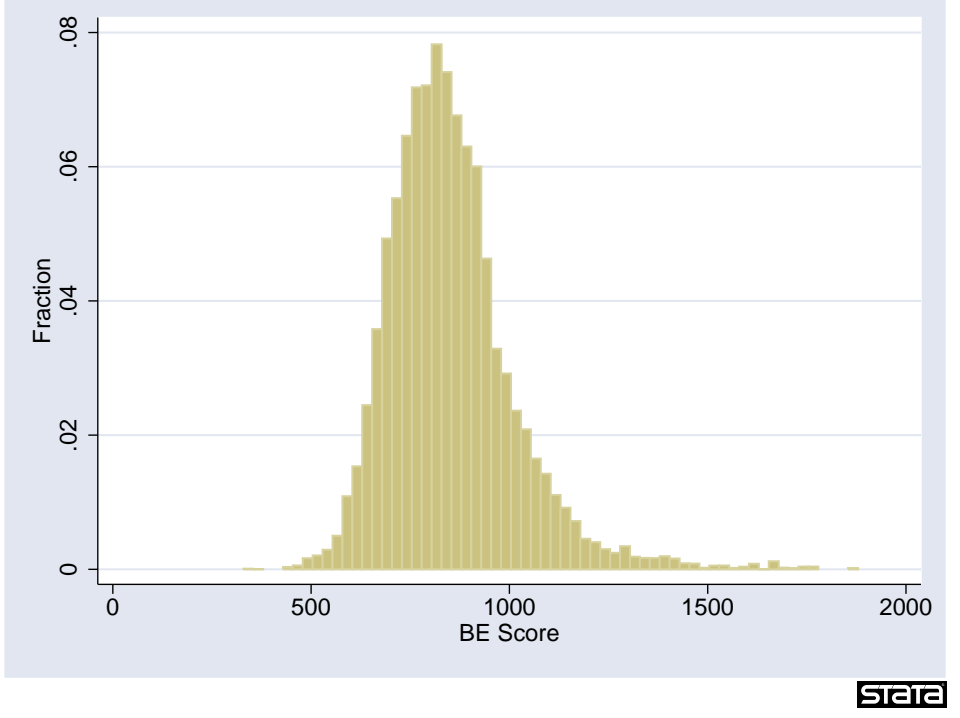

Figure 6: BE score of all the firms on the certified contractor lists 


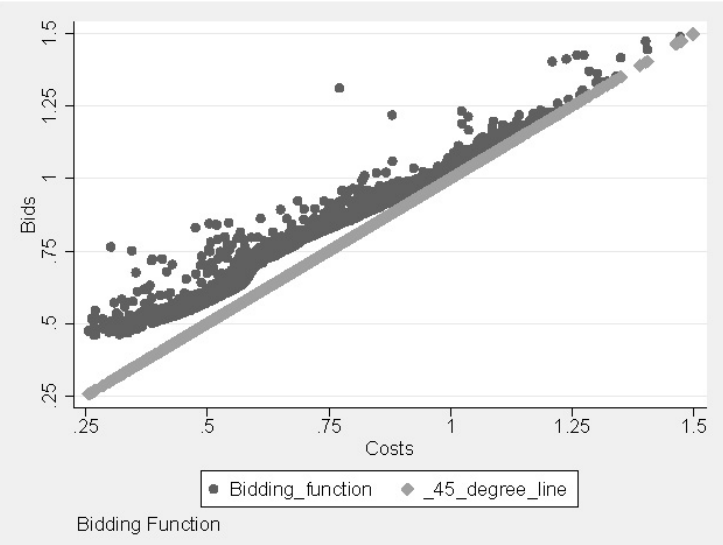

Figure 7: Few bidders: $n=5$

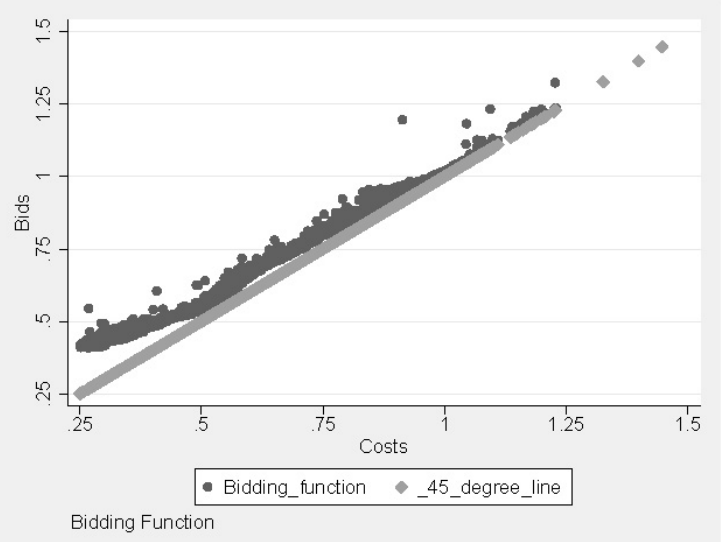

Figure 8: Many bidders: $22 \leq n \leq 28$

Time Line

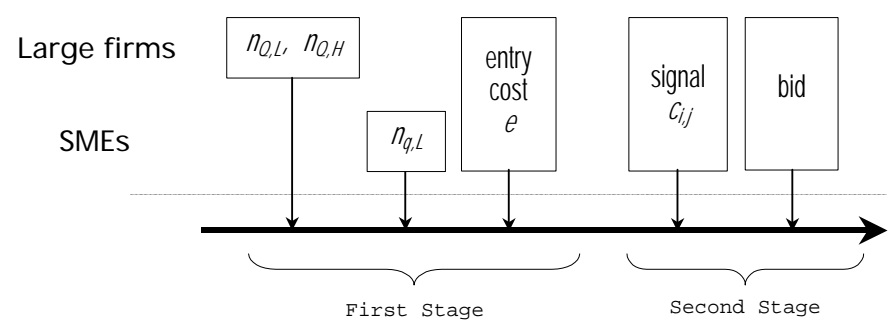

Figure 9: The model of auctions with entry 


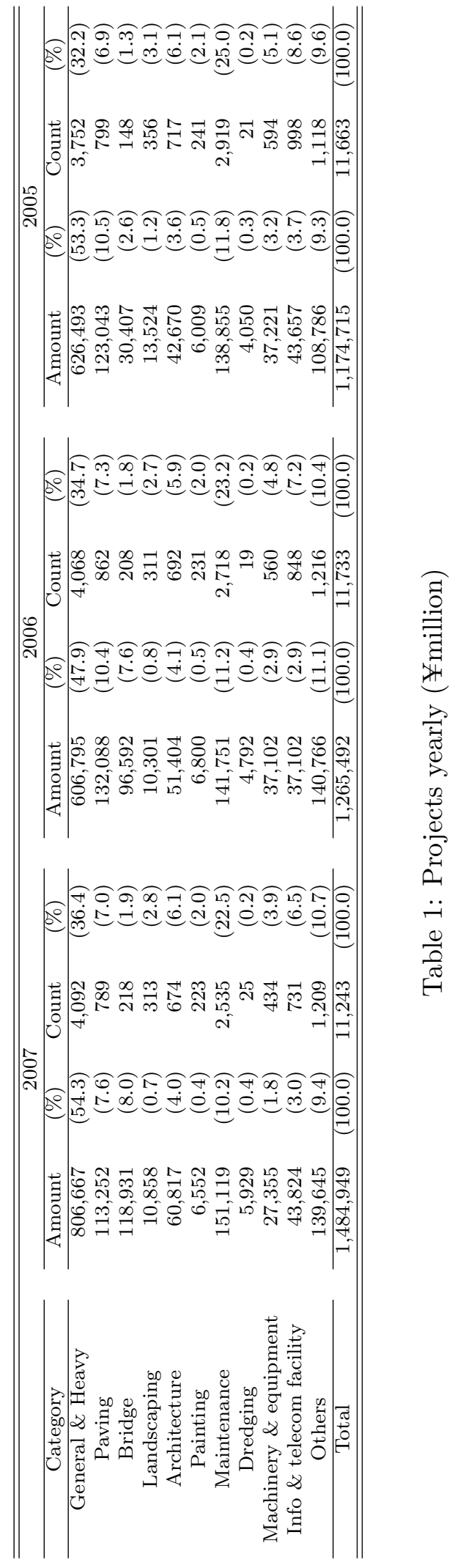

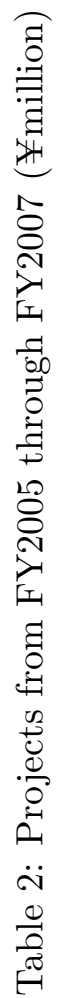




\begin{tabular}{cccccccc}
\hline \hline & & No. Obs. & Mean & Std.Dev. & CV $^{*}$ & Max & Min \\
\hline BE Score & $: X_{i, k}$ & 100,585 & $1,017.18$ & 133.58 & 0.132 & 1,859 & 506 \\
Normalized Score & $: x_{i, k}$ & 100,438 & -.001 & .074 & - & 0.50 & -.423 \\
\hline
\end{tabular}

Table 3: Summary statistics : The business evaluation score of actual bidders

\begin{tabular}{cccccc}
\hline \hline & & & & $¥$ Million* $^{*}$ \\
Project & No. & \multicolumn{3}{c}{ Engineer’s Estimated Costs } \\
\cline { 3 - 6 } Size & Observation & Mean & Std.Dev. & Max & Min \\
\hline 730 or more & 228 & $1,974.13$ & $1,458.72$ & $10,490.00$ & 737.90 \\
$300-730$ & 521 & 469.09 & 115.00 & 717.00 & 300.10 \\
$60-300$ & 8,851 & 141.55 & 63.23 & 300.00 & 60.01 \\
60 or less & 1,514 & 37.69 & 17.01 & 59.99 & .01 \\
\hline Total & 11,114 & 180.35 & 348.14 & $10,490.00$ & .01 \\
\hline \hline
\end{tabular}

Table 4: Summary statistics on project size

\begin{tabular}{|c|c|c|c|c|c|c|}
\hline & \multicolumn{3}{|c|}{ Bids } & \multicolumn{3}{|c|}{ Costs } \\
\hline & OLS & $\mathrm{FE}$ & $\mathrm{RE}$ & OLS & $\mathrm{FE}$ & $\mathrm{RE}$ \\
\hline$x_{i, k}$ & $\begin{array}{c}-0.030 \\
(4.66)^{* *}\end{array}$ & $\begin{array}{c}-0.024 \\
(6.03)^{* *}\end{array}$ & $\begin{array}{l}-0.024 \\
(6.15)^{* *}\end{array}$ & $\begin{array}{l}0.038 \\
(5.52)^{* *}\end{array}$ & $\begin{array}{c}-0.030 \\
(6.99)^{* *}\end{array}$ & $\begin{array}{c}0.031 \\
(7.12)^{* *}\end{array}$ \\
\hline Auction date & $\begin{array}{c}(88.95)^{* *} \\
0.014\end{array}$ & - & - & $\begin{array}{c}(90.76)^{* *} \\
0.012\end{array}$ & - & - \\
\hline Scoring auction dummy & $\begin{array}{c}(4.66)^{* *} \\
-0.063\end{array}$ & - & - & $\begin{array}{c}(5.52)^{* *} \\
-0.079\end{array}$ & - & - \\
\hline Auction form dummy 2 & $\begin{array}{c}(88.95)^{* *} \\
0.014\end{array}$ & - & - & $\begin{array}{c}(90.76)^{* *} \\
0.012\end{array}$ & - & - \\
\hline Auction form dummy 3 & $\begin{array}{c}(4.69)^{* *} \\
0.043\end{array}$ & - & - & $\begin{array}{c}(3.72)^{* *} \\
0.039\end{array}$ & - & - \\
\hline Auction form dummy 4 & $\begin{array}{c}(21.80)^{* *} \\
0.013\end{array}$ & - & - & $\begin{array}{c}(21.80)^{* *} \\
0.013\end{array}$ & - & - \\
\hline Constant & $\begin{array}{c}(89.55)^{* *} \\
86751\end{array}$ & $\begin{array}{c}(2951.12)^{* *} \\
86751\end{array}$ & $\begin{array}{c}(579.76)^{* *} \\
86751\end{array}$ & $\begin{array}{c}(91.29)^{* *} \\
86751\end{array}$ & $\begin{array}{c}(2538.72)^{* *} \\
86751\end{array}$ & $\begin{array}{c}(489.66)^{* *} \\
86751\end{array}$ \\
\hline Observations & 86751 & 86751 & 86751 & 86751 & 86751 & 86751 \\
\hline R-squared & 0.31 & 0.00 & - & 0.33 & 0.00 & - \\
\hline Number of auctions & - & 11058 & 11058 & - & 11058 & 11058 \\
\hline
\end{tabular}

Table 5: Regression results of normalized bids and estimated costs 


\begin{tabular}{|c|c|c|c|}
\hline & OLS & Robust OLS & $\overline{\mathrm{FE}}$ \\
\hline$x_{i j}$ & $\begin{array}{c}0.36 \\
(6.49)^{* *}\end{array}$ & $\begin{array}{c}0.36 \\
(6.04)^{* *}\end{array}$ & $\begin{array}{c}0.336 \\
(6.22)^{* *}\end{array}$ \\
\hline No. Bidders & $\begin{array}{c}-0.082 \\
(86.19)^{* *}\end{array}$ & $\begin{array}{c}-0.082 \\
(49.47)^{* *}\end{array}$ & $\begin{array}{c}-0.081 \\
(80.87)^{* *}\end{array}$ \\
\hline Auction date & $\begin{array}{c}-0.005 \\
(0.62)\end{array}$ & $\begin{array}{c}-0.005 \\
(0.65)\end{array}$ & \\
\hline $\mathrm{EST}_{k}$ & $\begin{array}{c}0.002 \\
(3.19)^{* *}\end{array}$ & $\begin{array}{c}0.002 \\
(2.87)^{* *}\end{array}$ & \\
\hline $\log \mathrm{EST}_{k}$ & $\begin{array}{l}0.008 \\
(0.97)\end{array}$ & $\begin{array}{l}0.008 \\
(0.91)\end{array}$ & \\
\hline Scoring auction dummy & $\begin{array}{c}0.144 \\
(5.72)^{* *}\end{array}$ & $\begin{array}{c}0.144 \\
(3.94)^{* *}\end{array}$ & \\
\hline Auction format dummy 1 & $\begin{array}{c}0.365 \\
(13.53)^{* *}\end{array}$ & $\begin{array}{c}0.365 \\
(9.75)^{* *}\end{array}$ & \\
\hline Constant & $\begin{array}{c}-2.745 \\
(18.61)^{* *}\end{array}$ & $\begin{array}{c}-2.745 \\
(17.27)^{* *}\end{array}$ & $\begin{array}{c}-2.38 \\
(15.60)^{* *}\end{array}$ \\
\hline $\begin{array}{l}\text { Observations } \\
\text { R-squared }\end{array}$ & $\begin{array}{l}7281 \\
0.54\end{array}$ & $\begin{array}{l}7281 \\
0.54\end{array}$ & 7281 \\
\hline No. auctions & & & 201 \\
\hline \multicolumn{4}{|c|}{$\begin{array}{l}\text { Absolute value of } \mathrm{t} \text { statistics in parentheses } \\
* \text { significant at } 5 \% ; * * \text { significant at } 1 \% \\
\text { FE controls auction specific effects. }\end{array}$} \\
\hline
\end{tabular}

Table 6: Regression result for bid margins

\begin{tabular}{cccccc}
\hline \hline Project Category & Mean & No. obs & Std. dev. & Max. & Min. \\
\hline $\begin{array}{c}\text { Low-end } \\
\text { \300 mn } \\
\text { High-end }\end{array}$ & 983.3 & 93,808 & 104.02 & 1,859 & 475 \\
$\geq ¥ 300 \mathrm{mn}$ & $1,370.9$ & 6,777 & 193.03 & 1,859 & 848 \\
\hline Total & $1,017.176$ & 100,585 & 151.19 & 1,859 & 475 \\
\hline \hline
\end{tabular}

Table 7: Project category 


\begin{tabular}{|c|c|c|c|c|}
\hline & & OLS & Robust OLS & FE \\
\hline$x_{i j}$ & $\left(\delta_{1}\right)$ & $\begin{array}{c}0.132 \\
(7.57)^{* *}\end{array}$ & $\begin{array}{c}0.132 \\
(7.59)^{* *}\end{array}$ & $\begin{array}{c}0.132 \\
(7.57)^{* *}\end{array}$ \\
\hline$(\text { No. Bidders })^{-1}$ & $\left(\delta_{2}\right)$ & $\begin{array}{c}1.01 \\
(83.35)^{* *}\end{array}$ & $\begin{array}{c}1.01 \\
(87.69)^{* *}\end{array}$ & $\begin{array}{c}1.009 \\
(76.08)^{* *}\end{array}$ \\
\hline Auction date & & $\begin{array}{l}0.001 \\
(0.22)\end{array}$ & $\begin{array}{l}0.001 \\
(0.23)\end{array}$ & $\begin{array}{l}0.001 \\
(0.55)\end{array}$ \\
\hline $\mathrm{EST}_{k}$ & & $\begin{array}{c}0 \\
(0.16)\end{array}$ & $\begin{array}{c}0 \\
(0.17)\end{array}$ & $\begin{array}{c}-0 \\
(0.02)\end{array}$ \\
\hline $\log \mathrm{EST}_{k}$ & & $\begin{array}{c}0 \\
(0.01)\end{array}$ & $\begin{array}{c}0 \\
(0.01)\end{array}$ & $\begin{array}{l}0.001 \\
(0.24)\end{array}$ \\
\hline Scoring auction dummy & & $\begin{array}{l}0.004 \\
(0.54)\end{array}$ & $\begin{array}{l}0.004 \\
(0.57)\end{array}$ & $\begin{array}{l}0.006 \\
(0.72)\end{array}$ \\
\hline Auction format dummy 1 & & $\begin{array}{c}-0.004 \\
(0.56)\end{array}$ & $\begin{array}{c}-0.004 \\
(0.58)\end{array}$ & $\begin{array}{l}-0.007 \\
(0.85)\end{array}$ \\
\hline Constant & & & & $\begin{array}{c}-0.013 \\
(0.23)\end{array}$ \\
\hline $\begin{array}{l}\text { Observations } \\
\text { R-squared }\end{array}$ & & $\begin{array}{c}56704 \\
0.23\end{array}$ & $\begin{array}{c}56704 \\
0.23\end{array}$ & $\begin{array}{c}56704 \\
0.1\end{array}$ \\
\hline \multicolumn{5}{|c|}{$\begin{array}{l}\text { Absolute value of } \mathrm{t} \text { statistics in parentheses } \\
* \text { significant at } 5 \% ;{ }^{* *} \text { significant at } 1 \% \\
\text { Except invited bidders }\end{array}$} \\
\hline
\end{tabular}

Table 8: Regression result for the linear probability model

\begin{tabular}{ccc}
\hline \hline & OLS & Robust OLS \\
\hline$x_{i j}\left(\alpha_{1}\right)$ & 1.361 & 1.361 \\
& $(17.20)^{* *}$ & $(16.81)^{* *}$ \\
No. Bidders $\left(\alpha_{2}\right)$ & -0.204 & -0.204 \\
& $(149.03)^{* *}$ & $(64.35)^{* *}$ \\
Constant $\left(\alpha_{0}\right)$ & -3.662 & -3.662 \\
& $(17.39)^{* *}$ & $(15.75)^{* *}$ \\
\hline & 7281 & 7281 \\
Observations & 0.77 & 0.77 \\
R-squared & Absolute value of t statistics in parentheses \\
$*$ significant at 5\%; & Ex significant at 1\% \\
Except invited bidders \\
\hline \hline
\end{tabular}

Table 9: Regression result for expected payoffs 


\begin{tabular}{|c|c|c|}
\hline & OLS & Robust OLS \\
\hline$x_{i j}\left(\alpha_{1}\right)$ & $\begin{array}{c}-0.083 \\
(4.88)^{* *}\end{array}$ & $\begin{array}{c}-0.07 \\
(4.79)^{* *}\end{array}$ \\
\hline No. bidders $\left(\alpha_{2}\right)$ & $\begin{array}{c}-0.003 \\
(11.43)^{* *}\end{array}$ & $\begin{array}{c}-0.004 \\
(14.85)^{* *}\end{array}$ \\
\hline Auction date & $\begin{array}{c}-0.121 \\
(51.55)^{* *}\end{array}$ & $\begin{array}{c}-0.122 \\
(51.55)^{* *}\end{array}$ \\
\hline $\mathrm{EST}_{k}$ & $\begin{array}{c}0.001 \\
(3.18)^{* *}\end{array}$ & $\begin{array}{c}0 \\
(3.18)^{* *}\end{array}$ \\
\hline $\log \mathrm{EST}_{k}$ & $\begin{array}{c}-0.068 \\
(29.72)^{* *}\end{array}$ & $\begin{array}{c}-0.062 \\
(29.72)^{* *}\end{array}$ \\
\hline Scoring auction dummy & $\begin{array}{c}-0.065 \\
(8.44)^{* *}\end{array}$ & $\begin{array}{c}-0.054 \\
(8.44)^{* *}\end{array}$ \\
\hline Auction format dummy 1 & $\begin{array}{l}-0.014 \\
(1.63)\end{array}$ & $\begin{array}{l}-0.007 \\
(1.63)\end{array}$ \\
\hline Constant & $\begin{array}{c}2.264 \\
(52.75)^{* *}\end{array}$ & $\begin{array}{c}2.157 \\
(52.75)^{* *}\end{array}$ \\
\hline Observations & 7728 & 7728 \\
\hline R-squared & 0.43 & 0.48 \\
\hline $\begin{array}{r}\text { Absolute value of } \mathrm{t} \\
* \text { significant at } 5 \% \\
\text { Except in }\end{array}$ & $\begin{array}{l}\text { atistics in p } \\
* * \text { significar } \\
\text { ited bidders }\end{array}$ & $\begin{array}{l}\text { rentheses } \\
\text { t at } 1 \%\end{array}$ \\
\hline
\end{tabular}

Table 10: Regression result for lowest bids 


\begin{tabular}{|c|c|c|c|c|}
\hline \multirow[b]{2}{*}{ Project category } & \multicolumn{2}{|c|}{ Set-asides } & \multicolumn{2}{|c|}{ Unrestricted } \\
\hline & Low & High* $^{*}$ & Low & High* $^{*}$ \\
\hline Mean no. small bidders & 7.87 & 0 & 4.86 & 0 \\
\hline Mean no. large bidders & 0 & 8.20 & 2.28 & 4.66 \\
\hline Mean no. total bidders & 7.87 & 8.20 & 7.14 & 4.66 \\
\hline Mean Scores & 983.3 & 1370.9 & 1107.2 & 1370.9 \\
\hline Procurement cost change & - & - & $-0.44 \%$ & $1.41 \%$ \\
\hline Overall effect & - & - & \multicolumn{2}{|c|}{$0.28 \%$} \\
\hline $\begin{array}{l}\text { Project volume ( } ¥ \text { bn.) } \\
\text { Sum of engineer's estimates } \\
\text { (Share \%) }\end{array}$ & $\begin{array}{c}1319.16 \\
(61.0)\end{array}$ & 851.80 & $\begin{array}{c}1319.16 \\
(61.0)\end{array}$ & $\begin{array}{r}851.80 \\
(39.0)\end{array}$ \\
\hline $\begin{array}{c}\text { Entry costs } \\
\text { (\% of engineer's estimates) }\end{array}$ & \multicolumn{2}{|c|}{$0.95 \%$} & \multicolumn{2}{|c|}{$0.95 \%$} \\
\hline $\begin{array}{l}\text { Profits (large firms) } \\
\text { (\% of engineer's estimates) }\end{array}$ & - & $0.96 \%$ & $1.79 \%$ & $1.79 \%$ \\
\hline
\end{tabular}

*High-end projects are those in which the engineer-estimated cost is no less than $¥ 300$ million.

Table 11: Estimation for the effect of set-asides 